\title{
Protein-based platform for purification, chelation, and study of medical radiometals: yttrium and actinium
}

Gauthier J.-P. Deblonde ${ }^{1,2 *}$, Joseph A. Mattocks ${ }^{3}$, Ziye Dong ${ }^{1}$, Paul T. Wooddy ${ }^{1}$, Joseph A. Cotruvo, Jr. ${ }^{3 *}$, Mavrik Zavarin ${ }^{1,2}$

${ }^{1}$ Physical and Life Sciences Directorate, Lawrence Livermore National Laboratory, Livermore, California 94550 , United States

${ }^{2}$ Glenn T. Seaborg Institute, Lawrence Livermore National Laboratory, Livermore, California 94550, United States

${ }^{3}$ Department of Chemistry, The Pennsylvania State University, University Park, Pennsylvania 16802, United States

\begin{abstract}
.
Actinium-based therapies could revolutionize cancer medicine but remain tantalizing due to the difficulties in studying Ac chemistry. Current efforts focus on small synthetic chelators, limiting radioisotope complexation and purification efficiencies. Here we demonstrate how a recently discovered protein, lanmodulin, can be utilized to efficiently bind, recover, and purify medicallyrelevant radiometals, actinium(III) and yttrium(III), and probe their chemistry. The stoichiometry, solution behavior, and formation constant of the ${ }^{228} \mathrm{Ac}-\mathrm{lanmodulin}$ complex $\left(\mathrm{Ac}_{3} \mathrm{LanM}, K_{\mathrm{d}}, 865\right.$ femtomolar) and its ${ }^{90} \mathrm{Y} /{ }^{\text {mat }} \mathrm{Y} /{ }^{\text {nat }} \mathrm{La}$ analogues were experimentally determined, representing both the first actinium-protein and most stable actinide(III)-protein species to be characterized. Lanmodulin's unparalleled properties enable the facile purification-recovery of radiometals, even in the presence of $>10^{+10}$ equivalents of competing ions and at ultra-trace levels: down to 2 femtograms ${ }^{90} \mathrm{Y}$ and 40 attograms ${ }^{228} \mathrm{Ac}$. The lanmodulin-based approach charts a new course to study elusive isotopes and develop versatile chelating platforms for medical radiometals, both for high-value separations and potentially in vivo applications.
\end{abstract}




\section{Introduction}

The use of radionuclides in medicine has been continuously growing over the past decades, especially in the case of short-lived radiometals, as they are among the most efficient means for medical imaging (e.g., PET and SPECT scans) and treatment of a wide array of diseases (e,g., bone metastasis, prostate cancers, and non-Hodgkin's lymphoma). ${ }^{1-3}$ In particular, actinium $\left(\mathrm{Ac}^{3+}\right)$ is largely seen as the most promising candidate for next-generation cancer treatments, i.e. targeted alpha therapy ${ }^{3-5}$. The nuclear properties of ${ }^{225} \mathrm{Ac}$ make it an ideal projectile against tumor cells (Figure S1): ${ }^{225} \mathrm{Ac}$ is a rare case of an alpha emitter with only short-lived daughters, decaying without leaving radioactive materials in the patient's body; its 9.95-day half-life is suitable for medical applications; its decay chain delivers, on average, 4 high-energy alpha plus 2 beta particles - leading to treatment efficacy hundreds of times higher ${ }^{6-8}$ than current medical radiometals. Therefore, if successful, the combined large-scale production, purification, and assembly of ${ }^{225} \mathrm{Ac}$ pharmaceuticals has the potential to revolutionize cancer medicine.

However, no ${ }^{225} \mathrm{Ac}$ drug has reached the market because of significant scientific challenges, from isotope production to the design of specific chelators for radiolabeled drugs. In fact, $\mathrm{Ac}^{3+}$ chemistry remains largely unknown compared to cations currently used in medicine $\left(\mathrm{Ga}^{3+}, \mathrm{Zr}^{4+}, \mathrm{Tc}^{5+17+}, \mathrm{Y}^{3+}\right.$, $\left.\mathrm{Gd}^{3+}, \mathrm{Lu}^{3+}, \mathrm{Sc}^{3+}, \mathrm{In}^{3+} \ldots\right)$ or other heavy radioelements for oncology $\left({ }^{223} \mathrm{Ra}^{2+},{ }^{227} \mathrm{Th}^{4+} \ldots\right)^{9,10}$, or even synthetic actinides discovered decades after actinium (Np, Pu, Am...), which impairs the development of any application involving actinium. Another barrier is the low availability of all Ac materials, even at the research scale. All Ac isotopes are radioactive (Figure 1a). The longestlived one, ${ }^{227} \mathrm{Ac}$ (21.8 years), would be suitable for chemical studies but it is cost prohibitive $\left(>1,000 \mathrm{USD} /\right.$ microgram) and difficult to produce and purify ${ }^{11,12} \cdot{ }^{225} \mathrm{Ac}$ is the main focus of medical research and multiple production routes are being investigated worldwide as the current 
isotope availability is much lower than the projected demand. Current production methods require particle accelerators, cyclotrons, or decades-old legacy nuclear materials, limiting ${ }^{225} \mathrm{Ac}$ availability. ${ }^{11,13-16}$ The ${ }^{235} \mathrm{U} /{ }^{231} \mathrm{~Pa}$ and ${ }^{233} \mathrm{U} /{ }^{229} \mathrm{Th}$ decay chains include ${ }^{227} \mathrm{Ac}$ and ${ }^{225} \mathrm{Ac}$, respectively, but these radionuclides have very long secular equilibrium periods (Figure S1, Table S1) and present nuclear proliferation issues, so they are tightly controlled and unlikely to make actinium more accessible. Consequently, there is no widely available generator from which Ac isotopes could be periodically extracted, forcing research laboratories willing to embark on actinium studies to purchase limited, expensive, and short-lived ${ }^{225} \mathrm{Ac}$ sources.

By contrast, ${ }^{228} \mathrm{Ac}$ (6.1 hours) occurs in the decay chain of ${ }^{232} \mathrm{Th}$, an inexpensive radioisotope that is abundant and already available at numerous industrial sites and research institutions. ${ }^{228} \mathrm{Ac}$ has been largely overlooked due to the lack of practical extraction methods since the mass of actinium isotopes in aged radioactive sources is extremely low (Table S1). After 10 years, 1 gram of ${ }^{232} \mathrm{Th}$ only contains $\sim 3.5 \times 10^{-14} \mathrm{~g}$ of ${ }^{228} \mathrm{Ac}$ - enough for radiochemical studies but beyond the capabilities of current Ac chelators. ${ }^{228} \mathrm{Ac}$ could become the most accessible Ac isotope and help to develop Ac chemistry as a whole, but only if an efficient and practical purification method can be implemented. 


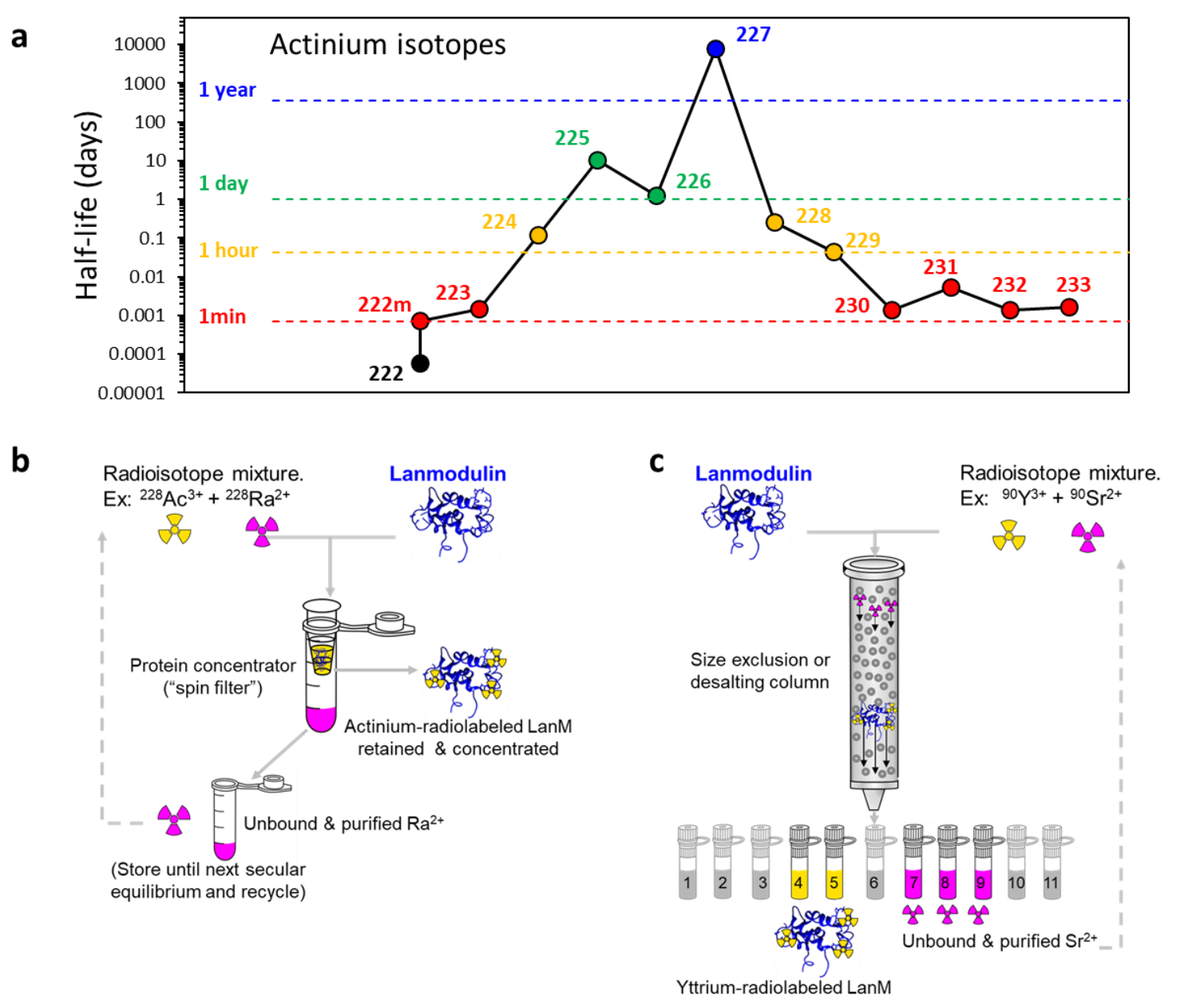

Figure 1. Actinium isotopes and protein-based radiometal recovery.

a, Half-lives of known actinium isotopes. ${ }^{225} \mathrm{Ac}$ is the principal actinium isotope studied for targeted-alpha therapies. ${ }^{227} \mathrm{Ac}$ is a research isotope and only produced at the microgram scale. Traces of ${ }^{227} \mathrm{Ac}$ are also present in aged ${ }^{235} \mathrm{U}$ or ${ }^{231} \mathrm{~Pa}$ materials. ${ }^{228} \mathrm{Ac}$ occurs in the decay chain of natural thorium $\left({ }^{232} \mathrm{Th}\right)$ at very low concentrations, requiring a highly efficient extraction system. The other isotopes are short-lived and rarely studied. b, Principle of the lanmodulin (LanM)-based one-step radioisotope separation method via centrifugation using the so-called "spin filters" or "protein concentrators". In this configuration, the protein is retained with the target isotope $\left(\mathrm{Y}^{3+}, \mathrm{Ac}^{3+} \ldots\right)$ while the low molecular weight fraction is eluted. The filtrates contain the purified unbound metals (e.g., radium, strontium, thorium). c, LanM-based metal separation performed using a size exclusion column (also called "desalting column"). In this configuration, the radiolabeled lanmodulin elutes prior to the unbound metals. The separation can be performed by gravity elution, pumped elution, or centrifugation. In both $\mathbf{b}$ and $\mathbf{c}$ scenarios, no matrix change or acidity adjustment is needed to recover the elements in separate fractions. The radiometal can be desorbed from LanM by decreasing $\mathrm{pH}(<2)$ or adding a chelator in excess. 
Here, we show that such a method can be realized using the protein lanmodulin (LanM), the first natural macrochelator selective for rare earths to be discovered, in $2018 .{ }^{17}$ Taking advantage of LanM's size, selectivity, and affinity, we purify ${ }^{228} \mathrm{Ac}$ and ${ }^{90} \mathrm{Y}$ from their generators $\left({ }^{232} \mathrm{Th} /{ }^{228} \mathrm{Ra}\right.$ and ${ }^{90} \mathrm{Sr}$ ) with unprecedented ease of implementation (Figure 1B-C). Furthermore, our method allows us to study the chemistry of $\mathrm{Ac}^{3+}$ with LanM and relevant bio-ligands for the first time, revealing a higher affinity than for the protein's natural substrates (lanthanides) and the highest stability constant reported for any $\mathrm{Ac}^{3+}$ complex, small molecules included. ${ }^{18}$ Because many radiometals are trivalent rare earths or actinides that LanM selectively binds and that would otherwise require cumbersome purification processes, our work suggests a general strategy for rapid radioisotope purification, detection, study, and perhaps even theranostic applications.

\section{Results and discussion}

Macromolecular purification of radioisotopes. The use of biomacromolecules, such as proteins, has largely been absent from purification strategies targeting radiometals like yttrium and actinium, as most known metal-binding proteins are not selective for f-elements. ${ }^{19-21}$ Even previous studies investigating interactions of proteins with uranium or heavy actinides (plutonium, americium, curium... $)^{22-24}$ have largely focused on bacterial and human iron or calcium transport machineries, which not only form relatively weak complexes with trivalent f-elements but also only operate under a very narrow set of conditions (typically $\mathrm{pH}>6$ and requiring a synergistic ligand like a carbonate or a siderophore molecule). By contrast, LanM displays unprecedented selectivity for trivalent lanthanides against most other cations. ${ }^{17,25,26}$ Instead of using minor differences in extraction reaction constants (as with current extractants, resulting in arduous metal ion separations $\left.{ }^{11,12}\right)$, a selective macromolecular extractant such as LanM $(\sim 12 \mathrm{kDa}$, hydrodynamic radius $\sim 4 \mathrm{~nm}^{26}$ ) would enable a new and more robust mechanism for recovery and purification of 
radiometals based on size differences. We hypothesized that protein-bound versus unbound metal ions could easily be separated using inexpensive methods like spin filtration or size exclusion chromatography (Figure 1b-c).

Short-lived radioisotopes require special handling but their actual concentration is very low (Table S1), necessitating extremely efficient and selective metal-binding molecules. To evaluate the protein-based radioisotopes purification strategy, we first attempted to recover ${ }^{90} \mathrm{Y}^{3+}$ from ${ }^{90} \mathrm{Sr}^{2+}$ sources using LanM. ${ }^{90} \mathrm{Y}$ is used for radioimmunotherapy and medical imaging (SPECT/CT, gamma, PET...). ${ }^{27,28}{ }^{90} \mathrm{Sr}$ has a long half-life (28.9 years) and $\beta$-decays to ${ }^{90} \mathrm{Y}$ (2.66 days). At secular equilibrium, the ratio ${ }^{90} \mathrm{Sr} /{ }^{90} \mathrm{Y}$ is $\sim 4,000 \mathrm{~mol} / \mathrm{mol}$. The ${ }^{90} \mathrm{Sr} /{ }^{90} \mathrm{Y}$ pair can be used as a generator for the short-lived ${ }^{90} \mathrm{Y}$ but, despite a sufficient stockpile of ${ }^{90} \mathrm{Sr}$, its global deployment has been hindered by difficulties in separating these isotopes efficiently, rapidly, and inexpensively. ${ }^{29}$

Figure 2a-d show the LanM-driven separation obtained after a single elution of an aqueous solution at $\mathrm{pH} 7$ containing a mixture of ${ }^{90} \mathrm{Sr} /{ }^{90} \mathrm{Y}$, initially at secular equilibrium. Efficient and quantitative separation of the two isotopes was observed after a single step and without requiring any eluant variation, loading/washing/elution cycles, or highly acidic extraction conditions. Such separation takes $<5$ min and could be even faster if automated. The presence of ${ }^{90} \mathrm{Y}$ in the high-molecularweight fraction and ${ }^{90} \mathrm{Sr}$ in the low-molecular-weight fraction was confirmed by monitoring the activity of the samples by liquid-scintillation counting (Figure 2b-d). The decay profiles of the protein fraction (Figure 2c) and small-molecule fraction (Figure S2) match exactly that of pure ${ }^{90} \mathrm{Y}$ and ${ }^{90} \mathrm{Sr}$, respectively. The energy spectra of the protein and low-molecular-weight fractions also match the fingerprint of the high-energy $\beta$ emitter ${ }^{90} \mathrm{Y}$ and low-energy $\beta$ emitter ${ }^{90} \mathrm{Sr}$, respectively (Figure 2d). After this one-step separation, the radiopurity of ${ }^{90} \mathrm{Y}$ increases from $50 \%$ to $99.9 \%$ 
(Figure S3). Similar attempts to separate ${ }^{90} \mathrm{Y}$ and ${ }^{90} \mathrm{Sr}$ using human apo-transferrin - a protein considered as the main $\mathrm{f}$-element transporter in mammals ${ }^{23,30,31}$ - failed due to the lower affinity and lack of selectivity of transferrin relative to LanM. Even under optimal conditions and at transferrin concentrations well above the level found in the bloodstream, less than $10 \%$ binding to ${ }^{90} \mathrm{Y}^{3+}$ was observed (Figure S4), highlighting that LanM is much more effective and selective than previously known lanthanide-binding proteins.

a

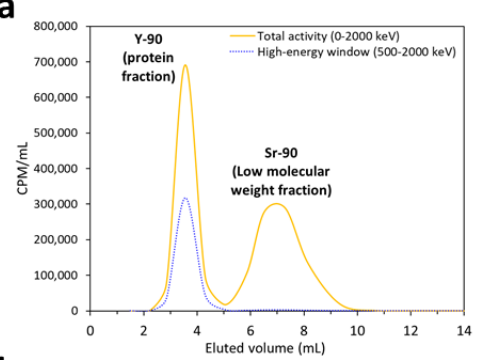

b

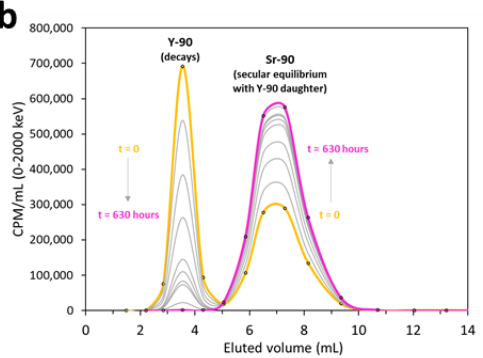

C

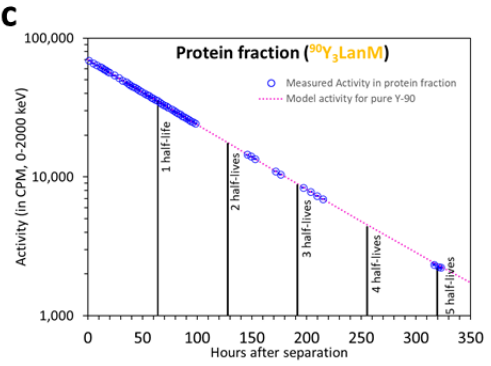

d

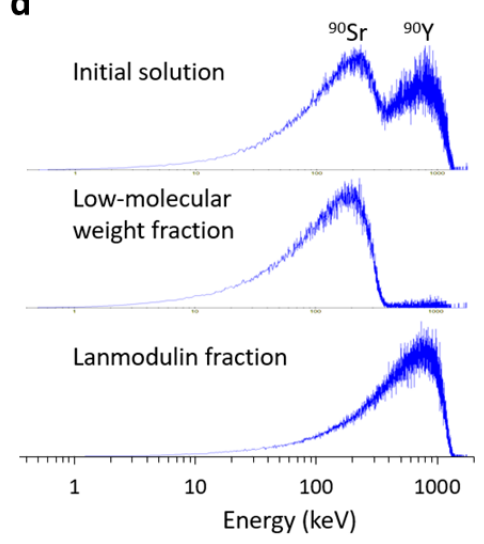

h

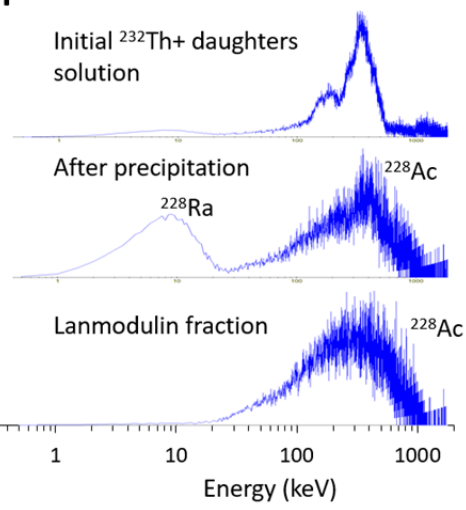

e

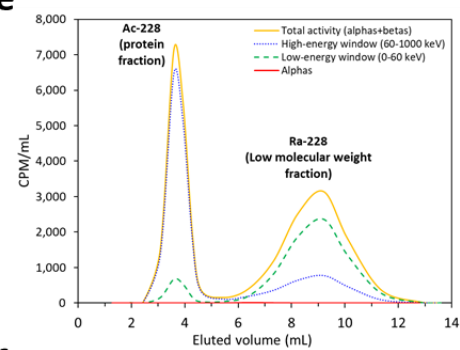

f

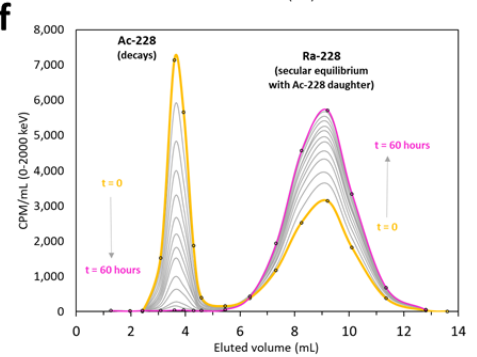

g

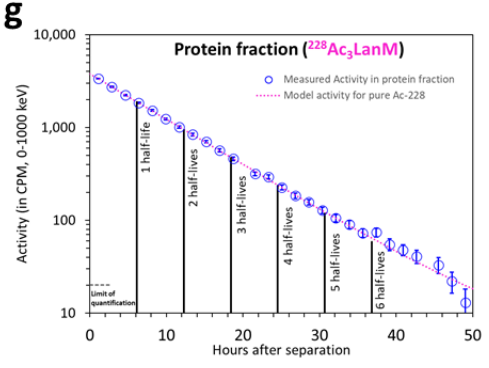

Figure 2. One-step extraction and purification of yttrium and actinium using LanM.

a, Typical elution profile of an ${ }^{90} \mathrm{Sr} /{ }^{90} \mathrm{Y}$ solution, initially at secular equilibrium, in the presence of LanM. $[\mathrm{LanM}]=50 \mu \mathrm{M}$. Activity $=37 \mathrm{kBq} / \mathrm{mL}$. Buffer: $90 \mathrm{mM} \mathrm{NaCl}, 10 \mathrm{mM}$ HEPES, $\mathrm{pH}=7.0$. b, c, Activity profile monitored at regular intervals, confirming the presence of high-purity ${ }^{90} \mathrm{Y}$ in the LanM fraction and quantitative separation ${ }^{90} \mathrm{Sr} /{ }^{90} \mathrm{Y}$. d, Energy spectra, measured by liquid scintillation, for the starting ${ }^{90} \mathrm{Sr} /{ }^{90} \mathrm{Y}$ solution (top), the low-molecular weight fraction (middle), and LanM fraction (bottom). Spectra are normalized to the count maxima. e, Typical elution profile of a ${ }^{228} \mathrm{Ra} /{ }^{228} \mathrm{Ac}$ solution, initially at secular equilibrium, in the presence of LanM. [LanM] $=25 \mu \mathrm{M}$. Buffer: $90 \mathrm{mM} \mathrm{NaCl}, 10 \mathrm{mM}$ HEPES, $\mathrm{pH}=7.0$. 
Note that pure ${ }^{228} \mathrm{Ac}$ inherently gives some counts in the low-energy window (green curve) due to the continuous nature of the beta emission. $\mathbf{f}, \mathbf{g}$, Activity profile monitored at regular intervals, confirming the presence of high-purity ${ }^{228} \mathrm{Ac}$ in the LanM fraction (Error bars or marker size $=2 \sigma$ ). $\mathbf{h}$, Typical energy spectra of a solution containing the ${ }^{232} \mathrm{Th}$ decay chain (top), the solution after hydroxide precipitation (middle), and the purified ${ }^{228} \mathrm{Ac}$ fraction using the LanM-based method (bottom).

The efficiency and selectivity of LanM for ${ }^{90} \mathrm{Y}^{3+}$ chelation suggests that it could be leveraged to complex actinium, even for its very short-lived isotope, ${ }^{228} \mathrm{Ac}$. Commercially available ${ }^{232} \mathrm{Th}$ salts exhibit measurable activity of ${ }^{228}$ Ac after a few months (Figure S5), albeit at extremely low concentration (Table S1). Being able to selectively recover ${ }^{228} \mathrm{Ac}^{3+}$ could make Ac chemistry readily available and independent from the cost-prohibitive and scarce ${ }^{227 / 225} \mathrm{Ac}$ sources. The ${ }^{232} \mathrm{Th}$ decay chain comprises ${ }^{228} \mathrm{Ra}$ (5.7 years) which decays to ${ }^{228} \mathrm{Ac}$, then ${ }^{228} \mathrm{Th}\left(1.9\right.$ years) and ${ }^{224} \mathrm{Ra}$ (3.6 days) (Figure S1). Starting from a ${ }^{232} \mathrm{Th}^{4+}$ nitrate solution, neutralization to $\mathrm{pH}$ 6-8 precipitates ${ }^{232} \mathrm{Th}$ and ${ }^{228} \mathrm{Th}$ as hydroxide, and co-precipitates the initial ${ }^{228} \mathrm{Ac}^{3+}$, leaving the two radium isotopes in solution. Without regeneration by ${ }^{228} \mathrm{Th},{ }^{224} \mathrm{Ra}$ and its daughters naturally decay within $\sim 20$ days (Figure S6). ${ }^{228}$ Ra regenerates ${ }^{228}$ Ac within $\sim 30$ hours, due to secular equilibrium, so it represents a potential ${ }^{228} \mathrm{Ra} /{ }^{228} \mathrm{Ac}$ generator (Figure S7). Little information has been published on the recovery of ${ }^{228} \mathrm{Ac}$ from macroscopic amounts of ${ }^{232} \mathrm{Th}$, besides a recent liquid-liquid extraction method performed in concentrated $\mathrm{HNO}_{3}$ media ${ }^{32}$, and an ion-exchange protocol including >30 steps $^{33}$ (Figure S8), which we deemed impractical for such a short-lived radioisotope. Additionally, we experimentally observed that the activity of ${ }^{228} \mathrm{Ra} /{ }^{228} \mathrm{Ac}$ solutions increases after $\sim 28$ days due to reformation of ${ }^{228} \mathrm{Th}$ from ${ }^{228} \mathrm{Ra}$ - a phenomenon predicted by the Bateman equation but overlooked in the literature - rendering previously proposed ${ }^{228} \mathrm{Ra} /{ }^{228} \mathrm{Ac}$ generators rapidly inoperable (Figure S6). By contrast, our LanM-based size-exclusion method offers direct, rapid, and practical extraction and purification of ${ }^{228} \mathrm{Ac}$ (Figure $\left.2 \mathrm{e}-\mathrm{h}\right)$. In none of the conditions tested did we observe interactions between $\mathrm{Ra}^{2+}$ and LanM, yielding high-purity ${ }^{228}$ Ac-lanmodulin fractions, as confirmed by radioactive decay monitoring and spectral identification (liquid 
scintillation and gamma spectroscopy - Figure 2h, Figure S3, Figure S9), even when starting from $\sim 8,200$ equivalents of ${ }^{228} \mathrm{Ra}$ or ${ }^{224} \mathrm{Ra} /{ }^{228} \mathrm{Ra} /{ }^{228} \mathrm{Ac}$ mixtures (Figure $\mathrm{S} 10$ ).

We were able to prepare ${ }^{228}$ Ac solutions with $\geq 99.5 \%$ radiopurity $\left(99.9 \%\right.$ for $\left.{ }^{90} \mathrm{Y}\right)$ on a daily basis, and at low cost, paving the way for investigating $\mathrm{Ac}^{3+}$ chemistry. Similar to ${ }^{90} \mathrm{Y} /{ }^{90} \mathrm{Sr}$, attempts to recover actinium using transferrin were unsuccessful (Figure S4). These results establish that LanM uniquely enables practical purification of valuable radioisotopes from generators, making ${ }^{90} \mathrm{Y}$ and ${ }^{228} \mathrm{Ac}$ more accessible for medical and chemical studies, and potentially extendable to other isotopes.

Lanmodulin enables facile detection of radiometals even at ultra-trace levels. To demonstrate the efficacy of the LanM-based extraction system and evaluate its limits, tests were performed with metal concentrations in the sub-nanomolar range, mimicking nuclear medicine conditions. ${ }^{6}$ Single-step separations of ${ }^{228} \mathrm{Ra} /{ }^{228} \mathrm{Ac}$ and ${ }^{90} \mathrm{Sr} /{ }^{90} \mathrm{Y}$ mixtures were performed using just $1 \mu \mathrm{M}$ LanM at pH 7 and without sample pre-concentration. Even under these unfavorable conditions for metal binding, LanM enables the efficient and selective scavenging of ${ }^{228} \mathrm{Ac}$ and ${ }^{90} \mathrm{Y}$. The ${ }^{90} \mathrm{Y}$ recovery yield in the protein fraction was maintained at $>75 \%$ for concentrations as low as $\sim 45 \mathrm{fM}$, or just $\sim 2$ femtogram of yttrium (Figure 3a). Below this level, uptake of ${ }^{90} \mathrm{Y}^{3+}$ by LanM was still observed, albeit with a lower yield (50-60\%). Even more remarkably, LanM has higher affinity for actinium, and it allows its selective recovery to a concentration as low as $0.3 \mathrm{fM}-$ just 40 attograms under the studied conditions (Figure 3b). Of note, this extremely low mass was only twice the instrumental quantification limit for ${ }^{228} \mathrm{Ac}$ so that more diluted samples were not investigated, but it is likely that the proposed LanM-based system works at even lower Ac levels (Figure S11). 
Furthermore, the metal uptake reactions with LanM are fast. After only a 5-minute incubation at room temperature and neutral $\mathrm{pH}$, the $\mathrm{Ac}^{3+}$-LanM binding reaction is almost complete (Figure $3 \mathrm{c}$ e). The results reinforce that the LanM-based approach could enable faster, more efficient, and low-cost purification of radioisotopes for medicine and research. It could also be adapted for the field-deployable analysis of radioisotopes, especially f-elements resulting from nuclear activities. 
a

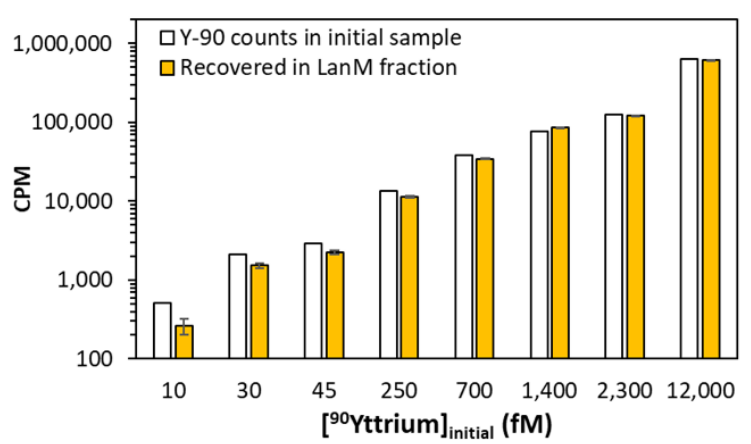

b

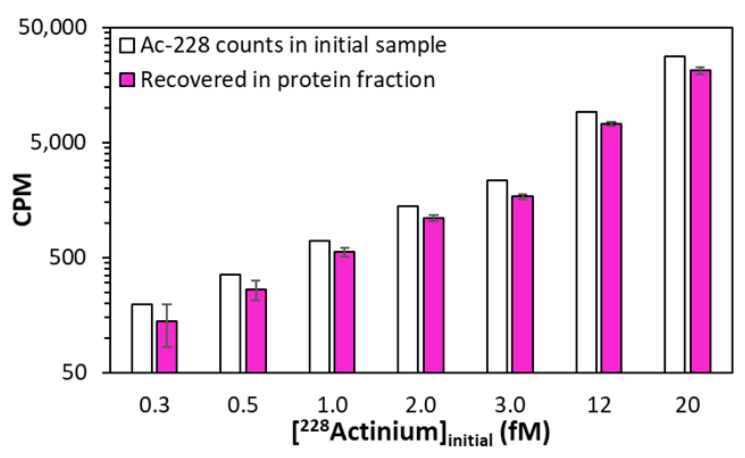

C

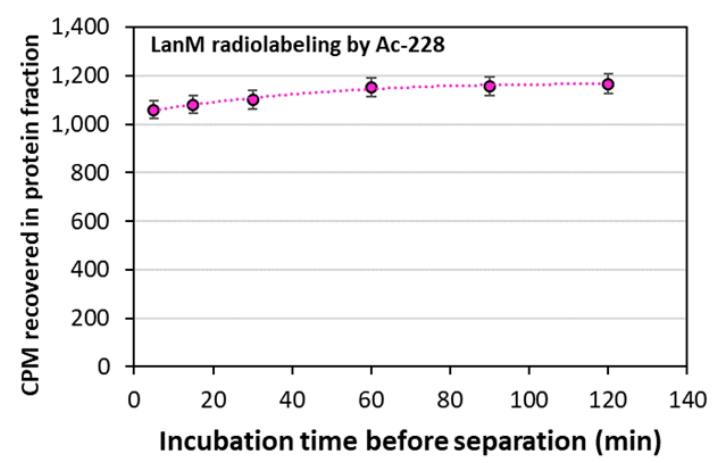

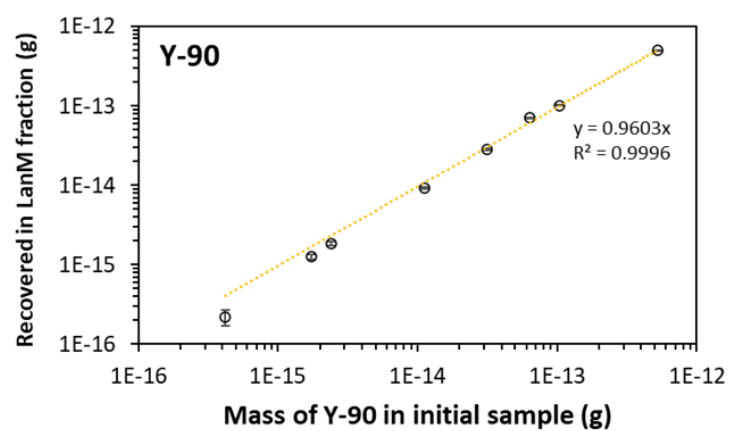
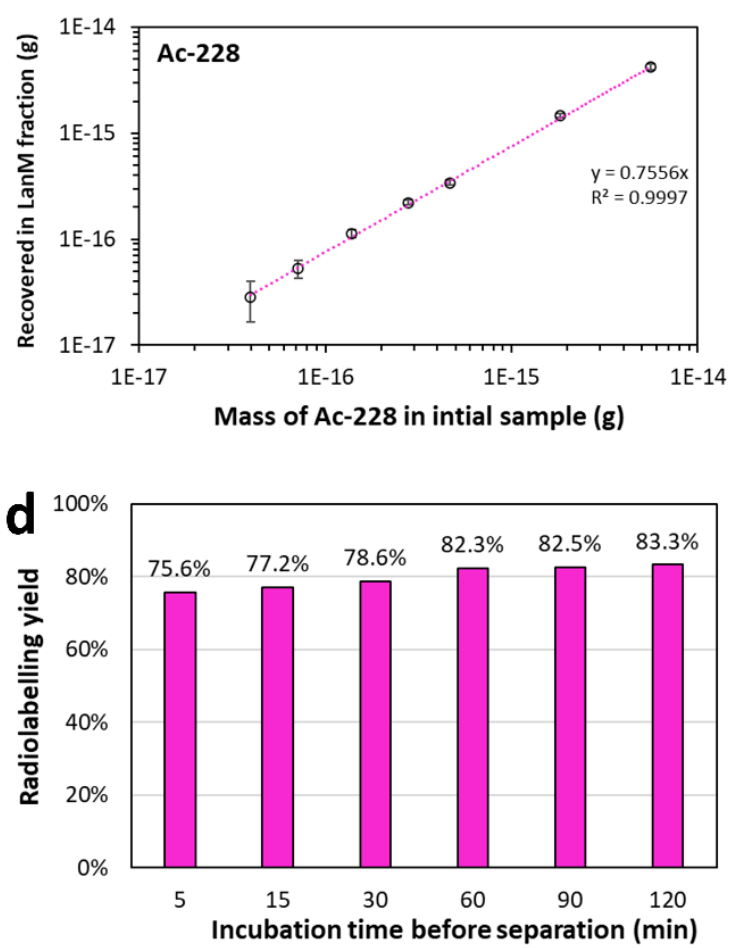

$\mathbf{e}$
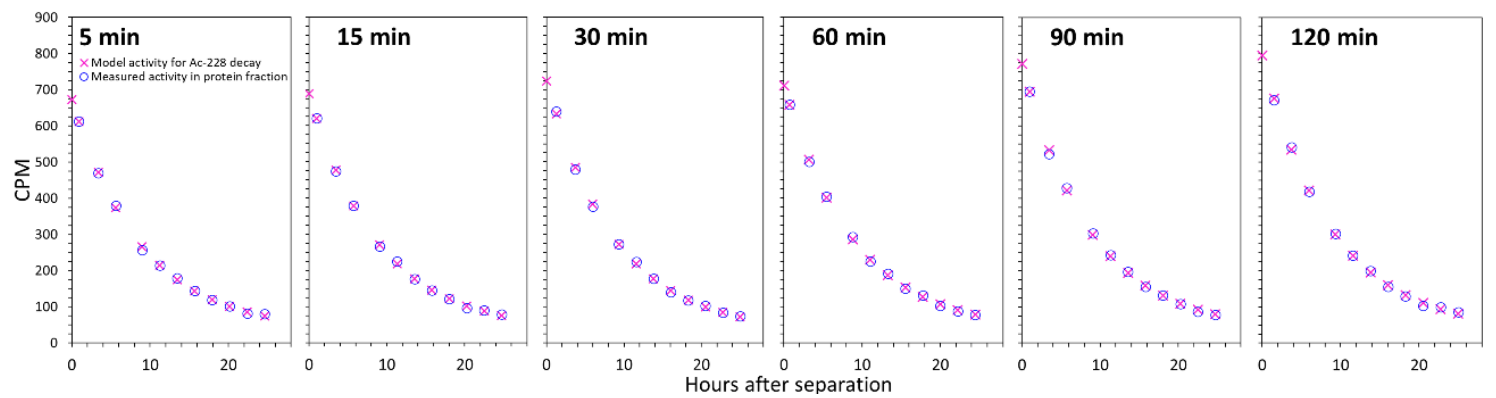

Figure 3. Recovery of $Y$ and Ac radioisotopes at ultra-low levels.

a, Activity and mass of ${ }^{90} \mathrm{Y}$ recovered in the protein fraction, compared to the total initial amount, following a single-step elution of ${ }^{90} \mathrm{Sr} /{ }^{90} \mathrm{Y}$ samples at various concentrations. [LanM] $=1 \mu \mathrm{M} . \mathrm{pH}=7.0$. b, Similar experiments with ${ }^{228} \mathrm{Ra} /{ }^{228} \mathrm{Ac}$ samples. c, d, Activity recovered in the protein fraction and radiolabeling yield following a single-step elution of ${ }^{228} \mathrm{Ra} /{ }^{228} \mathrm{Ac}$ samples, as a function of the incubation period. [LanM] $=10 \mu \mathrm{M}$. Room temperature. Buffer: $10 \mathrm{mM}$ HEPES, $90 \mathrm{mM} \mathrm{NaCl}, \mathrm{pH}$ 7. e, Radioactive decay curve of the protein fractions obtained following different incubation periods (5 to $120 \mathrm{~min}$ ) and elution through a 
size-exclusion column. The model radioactive decay for pure ${ }^{228} \mathrm{Ac}$ (crosses) is plotted for comparison with the experimental data (circles). The error bars correspond to $\pm 3 \sigma$.

Solution thermodynamics of actinium-lanmodulin. The combined preparation of ${ }^{228} \mathrm{Ac}$ solutions, efficient binding to LanM, and separation of the LanM complexes from small molecules afford a unique opportunity to probe the chemistry of actinium. While solution chemistry and crystallographic studies have been performed on f-element/protein species since the 1960's ${ }^{34,35}$, including with heavy actinides ${ }^{36,37}$, no actinium-protein complex has ever been characterized, even from a solution thermodynamic standpoint. This situation is due to the low availability of Ac isotopes, lack of $\mathrm{Ac}^{3+}$-specific spectroscopic features, and incompatibility of proteins with classic techniques used for radiotracers, like liquid-liquid extraction. ${ }^{38,39}$ Even for small $\mathrm{Ac}^{3+}$ complexes, no stability constant has been experimentally determined since the 1970's, with the strongest species reported being $[\text { AcEDTA }]^{-}\left(\log \beta_{11}=14.2\right){ }^{18,40}$

Here, we developed a combined radiochemical and size exclusion chromatography method relying on the natural dissociation of metal-chelator complexes at low concentration (Methods). To establish the method, the formation constant of ${ }^{90} \mathrm{Y}_{3} \operatorname{LanM}\left(\log \beta_{31}\right)$ was determined to be $33.9( \pm 0.5)$ at $\mathrm{pH} 7$, corresponding to an average dissociation constant $\left(K_{\mathrm{d}}\right)$ of $4.3( \pm 1.5) \mathrm{pM}$ per binding site (Figure 4a-b, Table S2). This value is in excellent agreement with results obtained using non-radioactive yttrium $\left(K_{\mathrm{d}, \text { app }}\left({ }^{\text {nat }} Y_{3} \operatorname{LanM}\right)=4.1 \pm 0.3 \mathrm{pM}\right.$. Figure $\left.\mathrm{S} 12\right)$ in ligand-protein titrations followed by circular dichroism (CD), confirming the applicability of the radiometry/dilution-based method. CD cannot be applied to actinium as each experiment would require milligram quantities of the element $(>1,000 \times$ the current world's supply) and knowledge of the stability constants between $\mathrm{Ac}^{3+}$ and the competing ligand, which are currently unknown. ${ }^{18}$ By contrast, the radiometry/dilution-based experiments only require femtograms of the radioisotope, and do not require a competing ligand. This approach revealed that LanM has very 
strong affinity for $\mathrm{Ac}^{3+}$, with a $\log \beta_{31}$ of $36.2 \pm 0.5$ for ${ }^{228} \mathrm{Ac}_{3} \mathrm{LanM}$ at $\mathrm{pH} 7$, equivalent to an average $K_{\mathrm{d}}$ of $865 \mathrm{fM}$ per site (Figure $4 \mathrm{c}-\mathrm{f}$ ). We previously showed ${ }^{17,26,41}$ that lanthanide ions form polymetallic complexes with $\mathrm{LanM}, \mathrm{Ln}_{3} \mathrm{LanM}$, at macroscopic concentrations (micromolar to millimolar range). However, LanM has four metal binding sites ${ }^{17}$ and it was unclear whether the fourth site could play a role in the binding of actinium. Combining the results obtained by the dilution-induced dissociation technique and speciation calculations confirms that the actiniumLanM complex is $\mathrm{Ac}_{3} \mathrm{LanM}$ (Figure S13). $\mathrm{Ac}_{3} \mathrm{LanM}$ is not only the first polynuclear actinium to be studied, but it also represents the most stable actinide(III)-protein complex.

CD experiments using $\mathrm{La}^{3+}$, a non-radioactive $\mathrm{Ac}^{3+}$ analogue, yielded a $K_{\mathrm{d}, \text { app }}$ of $1.8( \pm 0.1) \mathrm{pM}$ for ${ }^{\text {nat }} \mathrm{La}_{3} \mathrm{LanM}$ (Figure S12). The sub-picomolar stability of $\mathrm{Ac}_{3} \mathrm{LanM}$ extends a trend previously noted for the early lanthanides ${ }^{17,26}$ where LanM displays higher affinity for cations with lower Lewis acidity (Figure 4f). This reversed preference is remarkable when compared to small chelators $^{42}$ used in medicine since they typically exhibit decreasing affinity ${ }^{43}$ as the metal gets larger (Figure S14), leading to weak $\mathrm{La}^{3+}$ or $\mathrm{Ac}^{3+}$ complexes. LanM's combination of high $\mathrm{Ac}^{3+}$ affinity, fast kinetics, and selectivity are unparalleled when compared to ligands currently used in clinical studies. For instance, DOTA, which is largely seen as the gold standard for medical radiometals, exhibits slow kinetics and requires elevated temperatures $\left(>70^{\circ} \mathrm{C}\right)^{44,45}$ to trigger metal chelation, hindering procedures involving biomolecules. From a thermodynamic perspective, DOTA and other small chelators are also orders of magnitude less selective than LanM for $\mathrm{Ac}^{3+}$ against cations naturally present in the bloodstream (Figure S15). Hence, contrary to what has been observed for small f-element complexes used in medicine ${ }^{46-48}, \mathrm{Ac}_{3} \mathrm{LanM}$ is inherently less prone to in vivo dissociation via transmetallation reactions. Moreover, LanM's multiple binding sites enable multi-isotope radiolabeling (verified here with ${ }^{90} \mathrm{Y} /{ }^{228}$ Ac. Figure S16-17), which could 
allow theranostic strategies using a single chelator. The thermodynamic stability of $\mathrm{Ac}_{3} \mathrm{LanM}$ also makes it resistant against endogenous metal-binding proteins like transferrin, whose two binding sites can accommodate trivalent f-elements. ${ }^{23,30,49}$ While the stability of the $\mathrm{Ac}_{2}$ Transferrin complex has never been measured, a literature review allowed its estimation based on an empirical correlation: $\log \beta\left(\mathrm{Ac}_{2}\right.$ Transferrin $)=10.9 \pm 2$, or $K_{\mathrm{d}}=3.5 \mu \mathrm{M}$ (Figure S18). Despite the large uncertainty inherent to the latter estimation, LanM's affinity for actinium is clearly several orders of magnitude higher than that of $\mathrm{Tf}$, and $\mathrm{Tf}$ is unable to bind to $\mathrm{Ac}^{3+}$ at low concentrations (Figure S11), which is in line with experimental observations. The results suggest that LanM could be the basis for new actinium pharmaceuticals, if sufficiently kinetically inert.
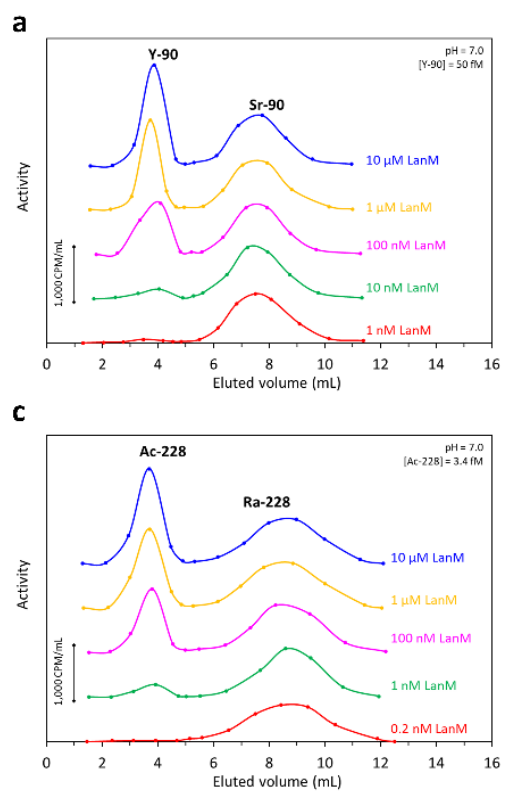

b

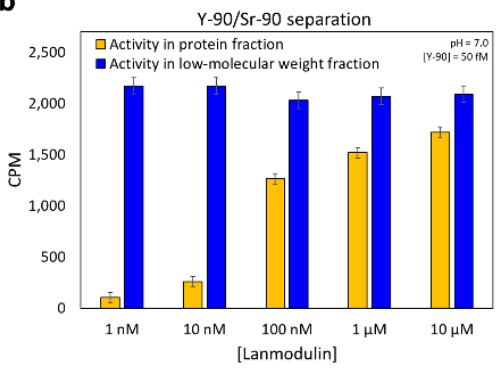

d

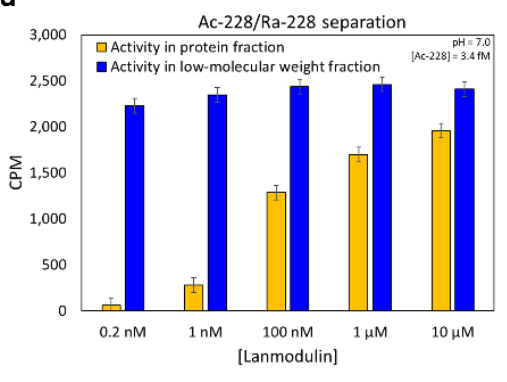

e

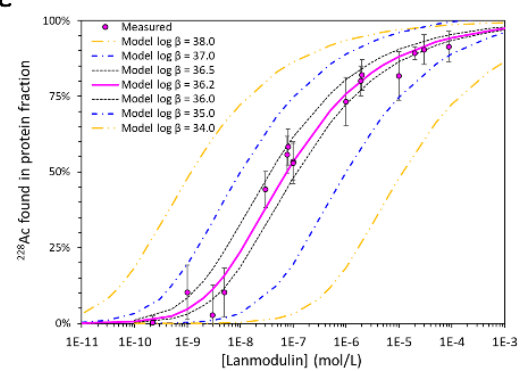

f

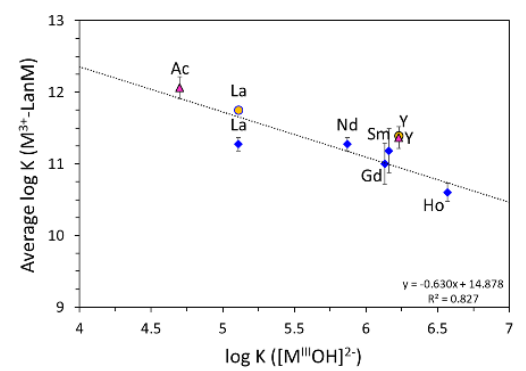

Figure 4. Stability of the actinium-lanmodulin complex.

a, Examples of elution profiles obtained with ${ }^{90} \mathrm{Y} /{ }^{90} \mathrm{Sr}$ at various concentrations of LanM. Buffer: $10 \mathrm{mM}$ HEPES, $90 \mathrm{mM} \mathrm{NaCl}, \mathrm{pH}$ 7.0, $22{ }^{\circ} \mathrm{C}$. Size exclusion column: Sephadex PD-10 (5 kDa MWCO). b, Radioactivity detected in the low-molecular-weight fraction $\left({ }^{90} \mathrm{Sr}\right)$ and protein fraction $\left({ }^{90} \mathrm{Y}\right)$ as a function of LanM concentration. c, Examples of elution profiles obtained with ${ }^{228} \mathrm{Ac} /{ }^{228} \mathrm{Ra}$ at various concentrations of LanM. Conditions similar to the ${ }^{90} \mathrm{Y} /{ }^{90} \mathrm{Sr}$ experiments. d, Radioactivity detected in the low-molecularweight fraction $\left({ }^{228} \mathrm{Ra}\right)$ and protein fraction $\left({ }^{228} \mathrm{Ac}\right)$ as a function of LanM concentration. e, Comparison of the experimental results and speciation models comprising ${ }^{228} \mathrm{Ac}_{3} \mathrm{LanM}$ with various stability constants, covering 4 orders of magnitude. The best fit of the experimental results is for $\log \beta_{31}\left({ }^{228} \mathrm{Ac}_{3} \mathrm{LanM}\right)=36.2$. f, Correlation between the Lewis acidity of the cations and the stability of their complexes with LanM. The 
average $K_{\mathrm{d}}$ per site is plotted against the first hydrolysis constant of the cation. The points for $\mathrm{Ac}^{3+}$ and $\mathrm{Y}^{3+}$ in magenta correspond to the radiochemical method; the points for $\mathrm{La}^{3+}$ and $\mathrm{Y}^{3+}$ in gold correspond to the $\mathrm{CD}$ method. Previous data $(\mathrm{CD}, \mathrm{pH} 7.2)^{17}$ are in blue. A similar correlation is given for transferrin in Figure S18.

Probing actinium chemistry using lanmodulin. The solution behavior of ${ }^{228} \mathrm{Ac}_{3} \mathrm{LanM}$ and ${ }^{90} \mathrm{Y}_{3}$ LanM was also evaluated. Size-exclusion chromatography assays showed that both complexes are resistant to acidic conditions, with LanM releasing its radioisotopes only below $\mathrm{pH} \sim 2.8$ (Figure 5a-b). Fitting of the binding curves as a function of $\mathrm{pH}$ using the Hill equation yields a high Hill coefficient (18.2 for Ac and 17.6 for Y). The sharp release of the metal upon acidification further supports the binding of $\mathrm{Ac}^{3+}$ (and $\mathrm{Y}^{3+}$ ) to the three binding sites of LanM. Following selective binding to LanM, both radiometals and protein can be recovered for further use by either lowering $\mathrm{pH}$ or adding a chelator in excess; we prepared $\mathrm{HCl}, \mathrm{HNO}_{3}$ as well as EDTA and DTPA solutions of ${ }^{228} \mathrm{Ac}$, with quantitative yield via one-step spin filtration from ${ }^{228} \mathrm{Ac}_{3} \mathrm{LanM}$ (Figure S18).

Extending our observation that neither ${ }^{228} \mathrm{Ra}^{2+}$ or ${ }^{90} \mathrm{Sr}^{2+}$ interact significantly with LanM, LanM's chelation of $\mathrm{Ac}^{3+}$ and $\mathrm{Y}^{3+}$ is also not impacted by the presence of cations that are ubiquitous in vivo and which interact with endogenous proteins and small chelators: $\mathrm{Ca}^{2+}, \mathrm{Mg}^{2+}, \mathrm{Mn}^{2+}, \mathrm{Zn}^{2+}$, and $\mathrm{Cu}^{2+}$. The use of short-lived ${ }^{228} \mathrm{Ac}$ and ${ }^{90} \mathrm{Y}$ allowed testing LanM's selectivity with mixtures containing up to $3 \times 10^{11}$ mol equivalents of each competing cation (Figure $5 \mathrm{c}$ ). Even under these extreme conditions, selective uptake of $\mathrm{Ac}^{3+}$ by LanM was still observed. For ${ }^{90} \mathrm{Y}_{3} \mathrm{LanM}$, a slight decrease in radiolabeling yield occurs above a billion-fold excess of divalent cations, corroborating the higher stability determined for ${ }^{228} \mathrm{Ac} c_{3} \mathrm{LanM}$ versus ${ }^{90} \mathrm{Y}_{3} \mathrm{LanM}$. Chelators currently used in nuclear medicine are unable to sustain such an excess of competing ions (Figure S15). 
Interestingly, differences were observed between $\mathrm{Ac}^{3+}$ and $\mathrm{Y}^{3+}$ relative to their interactions with small anions present in the bloodstream (Figure 5D-H). A high concentration of sulfate, acetate, or glycine does not destabilize ${ }^{228} \mathrm{Ac}_{3} \mathrm{LanM}$ or ${ }^{90} \mathrm{Y}_{3} \mathrm{LanM}$. However, at high concentration, carbonate and selenite ions compete with LanM and decrease its radiolabeling efficiency for ${ }^{90} \mathrm{Y}$ whereas $\mathrm{Ac}_{3} \mathrm{LanM}$ is unaffected. In the case of phosphate ions, ${ }^{228} \mathrm{Ac}_{3} \mathrm{LanM}$ was found more sensitive than ${ }^{90} \mathrm{Y}_{3} \mathrm{LanM}$. The observed trends $\left(\mathrm{PO}_{4}{ }^{3-}>\mathrm{CO}_{3}{ }^{2-} \approx \mathrm{SeO}_{3}{ }^{2-}\right.$ for actinium versus $\mathrm{CO}_{3}{ }^{2-}$ $>\mathrm{SeO}_{3}{ }^{2-}>\mathrm{PO}_{4}{ }^{3-}$ for yttrium) shed light on subtle chemical differences between actinium and rare earth elements that could be leveraged for separation purposes.
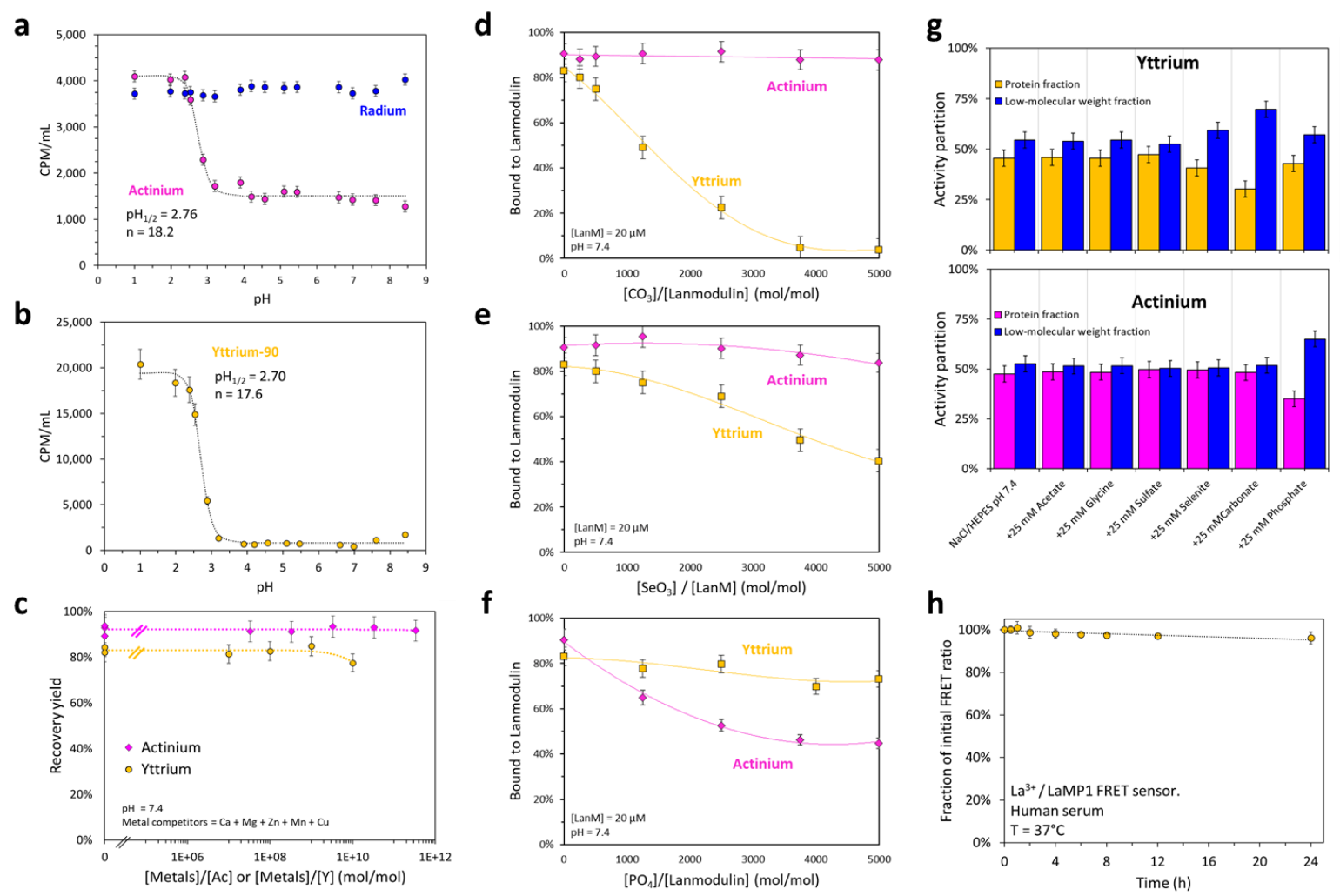

Figure 5. Solution chemistry of actinium in the presence of LanM.

a, Activity detected in the low-molecular-weight fraction as a function of $\mathrm{pH}$, after filtration (20 min, $12,000 \times g$, VivaSpin $3 \mathrm{kDa}$ ) of ${ }^{228} \mathrm{Ra} /{ }^{228} \mathrm{Ac}$ solutions, initially at secular equilibrium. $22{ }^{\circ} \mathrm{C} . \mathrm{I}=0.1 \mathrm{M}(\mathrm{NaCl})$. The dotted line corresponds to the fit using the Hill equation $(n=$ Hill coefficient $)$. $\mathbf{b}$, Same experiments with ${ }^{90} \mathrm{Y}$. c, ${ }^{228} \mathrm{Ac}$ or ${ }^{90} \mathrm{Y}$ recovered in the LanM fraction in the presence of $\mathrm{Ca}^{2+}, \mathrm{Mg}^{2+}, \mathrm{Mn}^{2+}, \mathrm{Zn}^{2+}$, and $\mathrm{Cu}^{2+}$. The $\mathrm{x}$-axis value is the concentration of each metal. PD-10 column, $20 \mu \mathrm{M}$ LanM, $10 \mathrm{mM}$ HEPES, $90 \mathrm{mM} \mathrm{NaCl}, \mathrm{pH}$ 7.4. d, Percentage of ${ }^{228} \mathrm{Ac}$ and ${ }^{90} \mathrm{Y}$ bound to LanM in the presence of carbonate ions. $\mathrm{pH}$ 
7.4, $10 \mathrm{mM}$ HEPES, $90 \mathrm{mM} \mathrm{NaCl}, 0$ to $100 \mathrm{mM} \mathrm{NaHCO}$. e, f, Similar experiments in selenite and phosphate media. g, Activity partition in the presence of biorelevant anions. $20 \mu \mathrm{M} \mathrm{LanM}, \mathrm{pH} 7.4,90 \mathrm{mM}$ $\mathrm{NaCl}, 10 \mathrm{mM}$ HEPES, $25 \mathrm{mM}$ biorelevant anions. ${ }^{228} \mathrm{Ac}$ and ${ }^{90} \mathrm{Y}$ experiments were done independently. Initial samples were at secular equilibrium. A perfect separation would yield $50 \%$ in each fraction. $\mathbf{h}$, Stability of $\mathrm{La}^{3+}$-bound complex of LaMP1 FRET sensor in 50\% human serum. $2 \mu \mathrm{M}$ LaMP1, $4 \mu \mathrm{M} \mathrm{La}$, $37^{\circ} \mathrm{C}$. The raw FRET ratios are also given in Figure S19.

While the direct interactions between $\mathrm{Ac}^{3+}$ and carbonate, selenite, or phosphate ions have never been probed under biorelevant conditions, our results indicate that $\mathrm{Ac}^{3+}$ exhibits stronger interactions with softer oxygen donors. In line with our experimental results, recent density functional theory calculations ${ }^{50}$ showed that replacing DOTA's carboxylate groups by phosphonate groups would impart enhanced stability for the $\mathrm{Ac}^{3+}$ complex. However, the design of new actinium complexants should also take into account the selectivity against natural cations, a challenge for most small molecules. Considering LanM's advantages relative to these chelators (e.g., fast kinetics, high selectivity and affinity, $\mathrm{pH}$ stability) we posit that the introduction of softer residues in LanM could lead to even more suitable Ac macrochelators. Finally, challenging $2 \mu \mathrm{M}$ $\mathrm{La}^{3+}$-LaMP1, a LanM-based fluorescent sensor $\left(K_{\mathrm{d}, \mathrm{app}}=9.4 \mathrm{pM}\right)^{25}$, with $50 \%$ human serum at $37^{\circ} \mathrm{C}$ reveals $\sim 5 \%$ loss of fluorescence response over $24 \mathrm{~h}$, indicating only minimal metal dissociation (Figure 5H, Figure S19). Given that $\mathrm{Ac}_{3} \mathrm{LanM}$ is $\sim 10$-fold tighter than $\mathrm{La}_{3} \mathrm{LaMP} 1$, these results suggest that $\mathrm{Ac}^{3+}$-LanM may be sufficiently stable for in vivo applications.

Conclusion. This study represents the first characterization of an actinium-protein complex, ${ }^{228} \mathrm{Ac}_{3}$ LanM. Our LanM-based separation strategy allows the efficient, practical, and concomitant chelation/purification of actinium (and ${ }^{90} \mathrm{Y}$ ), down to the femtomolar level, and is certainly translatable to other radiometals $\left({ }^{44 / 47} \mathrm{Sc},{ }^{177} \mathrm{Lu},{ }^{241} \mathrm{Am} ..\right)$. We envision that a similar biomacromolecular approach could be implemented to study other elusive elements, notably $\mathrm{Es}^{3+}$, $\mathrm{Fm}^{3+}$, and $\mathrm{Md}^{3+}$, for which several picograms can be produced but have remained inaccessible with current methodologies. Finally, the stability of LanM's complex with actinium is similar to 
those of its native substrates (lanthanides), and in the same range as siderophores considered to play a role in the mobilization of actinides and radiolanthanides in the environment. ${ }^{51}$ Therefore, our results raise questions about the influence of natural proteins such as LanM on the binding and transport of natural or anthropogenic radionuclides in the environment. Just as LanM has helped to incorporate the lanthanides into the bioinorganic periodic table, it promises to facilitate understanding of the interactions between actinides and biological systems, as well as the development of the chemistry of actinium and other rare isotopes for both research and medicine.

\section{References}

1. Wadas, T. J., Wong, E. H., Weisman, G. R. \& Anderson, C. J. Coordinating Radiometals of Copper, Gallium, Indium, Yttrium, and Zirconium for PET and SPECT Imaging of Disease. Chem. Rev. 110, 2858-2902 (2010).

2. Álvarez, N. H., Bauer, D., Hernández-Gil, J. \& Lewis, J. S. Recent Advances in Radiometals for Combined Imaging and Therapy in Cancer. ChemMedChem n/a, (2021).

3. Boros, E. \& Packard, A. B. Radioactive Transition Metals for Imaging and Therapy. Chem. Rev. 119, 870-901 (2019).

4. Thiele, N. A., Woods, J. J. \& Wilson, J. J. Implementing f-Block Metal lons in Medicine: Tuning the Size Selectivity of Expanded Macrocycles. Inorg. Chem. 58, 10483-10500 (2019).

5. Kratochwil, C. et al. 225Ac-PSMA-617 for PSMA-Targeted $\alpha$-Radiation Therapy of Metastatic Castration-Resistant Prostate Cancer. J Nucl Med 57, 1941-1944 (2016).

6. Graf, F. et al. DNA Double Strand Breaks as Predictor of Efficacy of the Alpha-Particle Emitter Ac-225 and the Electron Emitter Lu-177 for Somatostatin Receptor Targeted Radiotherapy. PLOS ONE 9, e88239 (2014). 
7. McDevitt, M. R. et al. Feed-forward alpha particle radiotherapy ablates androgen receptor-addicted prostate cancer. Nat Commun 9, 1-11 (2018).

8. Miederer, M., Scheinberg, D. A. \& McDevitt, M. R. Realizing the potential of the Actinium-225 radionuclide generator in targeted alpha particle therapy applications. Advanced Drug Delivery Reviews 60, 1371-1382 (2008).

9. Parker, C. et al. Alpha Emitter Radium-223 and Survival in Metastatic Prostate Cancer. New England Journal of Medicine 369, 213-223 (2013).

10. Wickstroem, K. et al. Synergistic Effect of a Mesothelin-Targeted 227Th Conjugate in Combination with DNA Damage Response Inhibitors in Ovarian Cancer Xenograft Models. Journal of Nuclear Medicine 60, 1293-1300 (2019).

11. Robertson, A. K. H. et al. 232Th-Spallation-Produced 225Ac with Reduced 227Ac Content. Inorg. Chem. 59, 12156-12165 (2020).

12. Abou, D. S., Pickett, J., Mattson, J. E. \& Thorek, D. L. J. A Radium-223 microgenerator from cyclotron-produced trace Actinium-227. Applied Radiation and Isotopes 119, 36-42 (2017).

13. Perron, R., Gendron, D. \& Causey, P. W. Construction of a thorium/actinium generator at the Canadian Nuclear Laboratories. Applied Radiation and Isotopes 164, 109262 (2020).

14. Apostolidis, C. et al. Cyclotron production of Ac-225 for targeted alpha therapy. Applied Radiation and Isotopes 62, 383-387 (2005).

15. Yan, W. Mining Medical Isotopes from Nuclear Waste. ACS Cent. Sci. 6, 827-829 (2020).

16. Boll, R. A., Malkemus, D. \& Mirzadeh, S. Production of actinium-225 for alpha particle mediated radioimmunotherapy. Applied Radiation and Isotopes 62, 667-679 (2005).

17. Cotruvo, J. A. Jr., Featherston, E. R., Mattocks, J. A., Ho, J. V. \& Laremore, T. N. Lanmodulin: A Highly Selective Lanthanide-Binding Protein from a Lanthanide-Utilizing Bacterium. J. Am. Chem. Soc. $140,15056-15061$ (2018). 
18. Kirby, H. W. \& Morss, L. R. Actinium. in The Chemistry of the Actinide and Transactinide Elements (eds. Morss, L. R., Edelstein, N. M. \& Fuger, J.) 18-51 (Springer Netherlands, 2006). doi:10.1007/14020-3598-5_2.

19. Ye, Y., Lee, H.-W., Yang, W., Shealy, S. \& Yang, J. J. Probing Site-Specific Calmodulin Calcium and Lanthanide Affinity by Grafting. J. Am. Chem. Soc. 127, 3743-3750 (2005).

20. Yang, J. J. et al. Rational Design of Protein-Based MRI Contrast Agents. J. Am. Chem. Soc. 130, 9260-9267 (2008).

21. Flo, T. H. et al. Lipocalin 2 mediates an innate immune response to bacterial infection by sequestrating iron. Nature 432, 917-921 (2004).

22. Seeger, P. A. et al. Neutron Resonance Scattering Shows Specific Binding of Plutonium to the Calcium-Binding Sites of the Protein Calmodulin and Yields Precise Distance Information. J. Am. Chem. Soc. 119, 5118-5125 (1997).

23. Jensen, M. P. et al. An iron-dependent and transferrin-mediated cellular uptake pathway for plutonium. Nat Chem Biol 7, 560-565 (2011).

24. Allred, B. E. et al. Siderocalin-mediated recognition, sensitization, and cellular uptake of actinides. PNAS 112, 10342-10347 (2015).

25. Mattocks, J. A., Ho, J. V. \& Cotruvo, J. A. Jr. A Selective, Protein-Based Fluorescent Sensor with Picomolar Affinity for Rare Earth Elements. J. Am. Chem. Soc. 141, 2857-2861 (2019).

26. Deblonde, G. J.-P. et al. Selective and Efficient Biomacromolecular Extraction of Rare-Earth Elements using Lanmodulin. Inorg. Chem. 59, 11855-11867 (2020).

27. Tickner, B. J., Stasiuk, G. J., Duckett, S. B. \& Angelovski, G. The use of yttrium in medical imaging and therapy: historical background and future perspectives. Chem. Soc. Rev. 49, 6169-6185 (2020).

28. Wright, C. L., Zhang, J., Tweedle, M. F., Knopp, M. V. \& Hall, N. C. Theranostic Imaging of Yttrium-90. BioMed Research International 2015, e481279 (2015). 
29. Therapeutic Radionuclide Generators: 90Sr/90Y and 188W/188Re Generators. (INTERNATIONAL ATOMIC ENERGY AGENCY, 2009).

30. Shinoda, S. \& Tsukube, H. Lanthanide Substitution of Iron-Containing Transferrin, Lactoferrin, and Ferritin, Development of Luminescent Reporter Proteins. in Encyclopedia of Metalloproteins (eds. Kretsinger, R. H., Uversky, V. N. \& Permyakov, E. A.) 1087-1091 (Springer, 2013). doi:10.1007/978-14614-1533-6_220.

31. Deblonde, G. J.-P., Sturzbecher-Hoehne, M., Mason, A. B. \& Abergel, R. J. Receptor recognition of transferrin bound to lanthanides and actinides: a discriminating step in cellular acquisition of $f$ block metals. Metallomics 5, 619-626 (2013).

32. Kazakov, A. G. et al. Generator of Actinium-228 and a Study of the Sorption of Actinium by Carbon Nanomaterials. Radiochemistry 62, 592-598 (2020).

33. Aldrich, K. E. et al. Preparation of an Actinium-228 Generator. Inorg. Chem. 59, 3200-3206 (2020).

34. Luk, C. K. Study of the nature of the metal-binding sites and estimate of the distance between the metal-binding sites in transferrin using trivalent lanthanide ions as fluorescent probes. Biochemistry 10, 2838-2843 (1971).

35. Sun, H., Li, H. \& Sadler, P. J. Transferrin as a Metal Ion Mediator. Chem. Rev. 99, 2817-2842 (1999).

36. Chipperfield, A. R. \& Taylor, D. M. Binding of Plutonium and Americium to Bone Glycoproteins. Nature 219, 609-610 (1968).

37. Deblonde, G. J.-P. et al. Chelation and stabilization of berkelium in oxidation state +IV. Nature Chemistry 9, 843-849 (2017).

38. Kelley, M. P. et al. Revisiting complexation thermodynamics of transplutonium elements up to einsteinium. Chem. Commun. 54, 10578-10581 (2018). 
39. Leguay, S. et al. New Insights into Formation of Trivalent Actinides Complexes with DTPA. Inorg. Chem. 51, 12638-12649 (2012).

40. Makarova, T. P., Sinitsyna, G. S., Stepanov, A. V., Shestakova, I. A. \& Shestakova, B. I. Complex formation of actinium. I. Determination of the stability constants of ethylenediaminetetraacetate complexes of actinium and its separation from lanthanum in solutions of EDTA by the method of electromigration. Soviet Radiochemistry 14, 555-557 (1972).

41. Cook, E. C., Featherston, E. R., Showalter, S. A. \& Cotruvo, J. A. Jr. Structural Basis for Rare Earth Element Recognition by Methylobacterium extorquens Lanmodulin. Biochemistry 58, 120-125 (2019).

42. Thiele, N. A. \& Wilson, J. J. Actinium-225 for Targeted $\alpha$ Therapy: Coordination Chemistry and Current Chelation Approaches. Cancer Biotherapy and Radiopharmaceuticals 33, 336-348 (2018).

43. Hu, A., MacMillan, S. N. \& Wilson, J. J. Macrocyclic Ligands with an Unprecedented Size-

Selectivity Pattern for the Lanthanide Ions. J. Am. Chem. Soc. 142, 13500-13506 (2020).

44. De León-Rodríguez, L. M. \& Kovacs, Z. The Synthesis and Chelation Chemistry of DOTA-Peptide Conjugates. Bioconjugate Chem. 19, 391-402 (2008).

45. Pérez-Malo, M. et al. Improved Efficacy of Synthesizing *MIII-Labeled DOTA Complexes in Binary Mixtures of Water and Organic Solvents. A Combined Radio- and Physicochemical Study. Inorg. Chem. 57, 6107-6117 (2018).

46. Greenberg, S. A. Zinc Transmetallation and Gadolinium Retention after MR Imaging: Case Report. Radiology 257, 670-673 (2010).

47. Telgmann, L. et al. Speciation of Gd-based MRI contrast agents and potential products of transmetalation with iron ions or parenteral iron supplements. Anal Bioanal Chem 404, 2133-2141 (2012).

48. Turyanskaya, A. et al. Detection and imaging of gadolinium accumulation in human bone tissue by micro- and submicro-XRF. Sci Rep 10, 1-9 (2020). 
49. Bauer, N., Fröhlich, D. R. \& Panak, P. J. Interaction of $\mathrm{Cm}$ (III) and Am(III) with human serum transferrin studied by time-resolved laser fluorescence and EXAFS spectroscopy. Dalton Trans. 43, $6689-6700$ (2014).

50. Stein, B. W. et al. Advancing Chelation Chemistry for Actinium and Other $+3 \mathrm{f}$-Elements, Am, $\mathrm{Cm}$, and La. J. Am. Chem. Soc. 141, 19404-19414 (2019).

51. Christenson, E. A. \& Schijf, J. Stability of YREE complexes with the trihydroxamate siderophore desferrioxamine B at seawater ionic strength. Geochimica et Cosmochimica Acta 75, 7047-7062 (2011).

\section{Acknowledgments}

This work was performed under the auspices of the U.S. Department of Energy (DOE) by Lawrence Livermore National Laboratory under Contract DE-AC52-07NA27344 (LLNL-JRNL-822758) and was supported by the LLNL-LDRD Program under Project No. 20-LW-017. J.A.M. and J.A.C. were supported by DOE grant DE-SC0021007. The authors thank Dr. Keenan J. Thomas (LLNL) for help with the gamma analyses and helpful discussions. The authors also thank Dr. Yongqin Jiao and Dr. Dan Park (LLNL) for comments on the manuscript and fruitful discussions.

\section{Author Information}

*Corresponding Authors: Deblonde1 @LLNL.gov (G.J.-P.D.) and juc96@psu.edu (J.A.C.)

\section{Competing interests}

The authors declare the following competing financial interests: G.J.-P.D., J.A.M., Z.D., and J.A.C. are listed as inventors on a patent application submitted by Lawrence Livermore National Laboratory and the Pennsylvania State University. 


\section{SUPPORTING}

\section{INFORMATION}

\section{Protein-based platform for purification, chelation, and study of medical radiometals: yttrium and actinium}

Gauthier J.-P. Deblonde ${ }^{1,2^{*}}$, Joseph A. Mattocks ${ }^{3}$, Ziye Dong ${ }^{1}$, Paul T. Wooddy ${ }^{1}$, Joseph A. Cotruvo, Jr. ${ }^{3 *}$, Mavrik Zavarin ${ }^{1,2}$

${ }^{1}$ Physical and Life Sciences Directorate, Lawrence Livermore National Laboratory, Livermore, California 94550, United States

${ }^{2}$ Glenn T. Seaborg Institute, Lawrence Livermore National Laboratory, Livermore, California 94550, United States ${ }^{3}$ Department of Chemistry, The Pennsylvania State University, University Park, Pennsylvania 16802, United States

*Corresponding Authors: Deblonde1@LLNL.gov (G.J.-P.D.) and juc96@psu.edu (J.A.C.) 


\section{Methods}

Caution! ${ }^{90} \mathrm{Sr}$ and ${ }^{232} \mathrm{Th}$, and concentrates of their decay products $\left({ }^{228} \mathrm{Ra},{ }^{228} \mathrm{Ac},{ }^{228} \mathrm{Th} \ldots\right)$, constitute serious health hazards because of their radioactive and chemical properties. Radiochemical experiments were conducted at LLNL in laboratories designed for the safe handling of short-lived and long-lived radioactive materials and associated waste.

Materials. Starting ${ }^{90} \mathrm{Sr} /{ }^{90} \mathrm{Y}$ solutions were prepared by dilution of a primary standardized stock (Eckert \& Ziegler, USA). Starting ${ }^{232}$ Th solutions were prepared by direct dissolution of $\mathrm{Th}\left(\mathrm{NO}_{3}\right)_{4} \cdot \mathrm{nH}_{2} \mathrm{O}$ salts purchased from Spex Industries (USA) and Strem Chemicals (USA). The age of the different ${ }^{232} \mathrm{Th}$ salts varied from $\sim 0.5$ to 20 years. Liquid scintillation and gamma analysis confirmed the presence of decay products. All aqueous solutions were prepared using deionized water purified by reverse osmosis. Buffers (VWR), non-radioactive chemicals (MilliporeSigma), PD-10 size exclusion columns (GE Healthcare), and Vivaspin ${ }^{\circledR}$ protein concentrators (Cytiva) were purchased and used as received. Wild-type LanM and LaMP1 were expressed and purified as previously described. ${ }^{1-3}$

Radioanalysis. Liquid scintillation counting (LSC) was performed with a Perkin Elmer TriCarb 5110TR instrument equipped with an alpha/beta discriminator. Calibration was performed on a daily basis. Samples were diluted in UltimaGold ${ }^{\mathrm{TM}}$ and results are background-corrected. Error bars displayed on the decay profile correspond to $\pm 2 \sigma$ unless otherwise indicated. Gamma analyses were performed using high-purity Ge (HPGe) coaxial p-type semiconductor detectors, each rated at (21\% and $37 \%$ standard efficiency relative to $3 \times 3 \mathrm{NaI})$. Energy and efficiency calibrations were performed with NIST-traceable standards. Samples were counted as $\sim 10 \mathrm{~mL}$ solutions in plastic vials $\left(10 \mathrm{~cm}^{2}\right.$ cross sectional area) at distances of $4-5 \mathrm{~cm}$ from the face of the detector endcaps for up to 6 hours. Spectra were processed using GAMANAL. ${ }^{4}$ 
Size exclusion separations. PD-10 columns prepacked with Sephadex G-25 media ( $8.3 \mathrm{~mL}, 5$ $\mathrm{kDa}$ MWCO) and VivaSpin500 concentrators (membrane with $3 \mathrm{kDa}$ MWCO) were preequilibrated with 5 bed volumes of buffer, as per the manufacturers' manuals. Sample volumes ranged from 0.4 to $3.0 \mathrm{~mL}$. For thermodynamic measurements, samples were equilibrated at least $1 \mathrm{~h}$ before elution. For PD-10 columns, the sample was injected, followed by addition of buffer $(\sim 12 \mathrm{~mL})$, and eluted by gravity. The elution lasts $5-10 \mathrm{~min}$. The macromolecules elute at $\sim 3 \mathrm{~mL}$ and the small molecules at $\sim 6-9 \mathrm{~mL}$. Individual fractions of 0.3 to $0.8 \mathrm{~mL}$ were collected and weighed for mass balance $(0.1 \mathrm{mg}$ accuracy). For spin filters, samples were centrifuged at 12,000×g, $20 \mathrm{~min}$. Each fraction was radioanalyzed immediately after separation and monitored over time as needed. See ESI for radiopurity calculations.

Protein $K_{d}$ determination by a radiometric- and dilution-based method. The solution thermodynamics stipulate that metal-ligand complexes dissociate at low concentrations:

$K d=\frac{[\text { Metal }]_{\text {free }} \times[\text { Ligand }]_{\text {free }}}{[\text { Complex }]}$

In the presence of a large excess of ligand, [Ligand $]_{\text {free }} \approx[\text { Ligand }]_{\text {total }}:$

$K d=\frac{\left([\text { Metal }]_{\text {total }}-[\text { Complex }]\right) \times[\text { Ligand }]_{\text {total }}}{[\text { Complex }]}$

$[$ Complex $]=\frac{[\text { Ligand }]_{\text {total }}}{K d+[\text { Ligand }]_{\text {total }}} \times[\text { Metal }]_{\text {total }}$

Size exclusion separations ( $\mathrm{pH} 7.0,10 \mathrm{mM}$ HEPES $+90 \mathrm{mM} \mathrm{NaCl}, 22 \pm 0.5^{\circ} \mathrm{C}, \mathrm{PD}-10$ ) were performed with varying LanM and metal concentrations. The initial solutions of ${ }^{228} \mathrm{Ac} /{ }^{228} \mathrm{Ra}$ were aged 28 days to avoid any contamination with ${ }^{224} \mathrm{Ra}$ and its daughters. At least 15 independent column separations were performed for both ${ }^{90} \mathrm{Y} /{ }^{90} \mathrm{Sr}$ and ${ }^{228} \mathrm{Ac} /{ }^{228} \mathrm{Ra}$ (12-15 fractions per column). Each fraction was measured over time by LSC to confirm the radionuclide identity. ${ }^{90} \mathrm{Sr}$ 
and ${ }^{228} \mathrm{Ra}$ were used as internal tracers. Each column separation allows determination of the fraction of bound and unbound $\mathrm{Y}^{3+}$ (Table S2) or $\mathrm{Ac}^{3+}$ (Figure 4e). As the metal and/or protein concentrations decrease, lower radiolabeling yields are observed for $\mathrm{Y}^{3+}$ and $\mathrm{Ac}^{3+}$, albeit at different levels. Knowing the metal partition and the total concentrations, each column experiment allows evaluating the formation of the metal-protein complex. Speciation calculations were performed with the computer program $H y S S^{5}$ and taking into account the metal hydrolysis constants. ${ }^{6}$ Under the studied conditions the metal hydroxide species account for $<1 \%$ for $\mathrm{Ac}^{3+}$ and $<15 \%$ for $\mathrm{Y}^{3+}$. The reported $\log \beta\left(\mathrm{M}_{3} \mathrm{LanM}\right)$ are the average of at least 15 column experiments $( \pm 1 \sigma)$.

Protein $K_{d}$ determination by $\mathbf{C D}$. The conformational response of LanM in the presence of EGTA-buffered La(III) and EDDS-buffered Y(III) solutions was measured using circular dichroism as previously described. ${ }^{1}$

Stability of La(III)-LaMP1 in serum. A solution of $10 \mathrm{mM} \mathrm{LaCl}_{3}$ was added to $140 \mu \mathrm{M} \mathrm{LaMP1}$ to a final metal:protein ratio of $2: 1$ and incubated at room temperature for $10 \mathrm{~min}$. Buffer A (20 mM MOPS-KOH, $140 \mathrm{mM} \mathrm{NaCl}, \mathrm{pH}$ 7.4, sterile filtered) and sterile-filtered human serum were individually incubated at $37^{\circ} \mathrm{C}$. La(III)-LaMP1 or apo-LaMP1 was added to pre-warmed buffer A to $4 \mu \mathrm{M}$, mixed 1:1 with serum, and incubated at $37^{\circ} \mathrm{C}$. At each time point, $100 \mu \mathrm{L}$ of each reaction mixture was placed in a Greiner 96-well $\mu$ CLEAR half-area plate and assayed on a BioTek Synergy H1 plate reader with $433 \mathrm{~nm}$ excitation and 460-550 nm emission (1 nm steps). FRET ratios were calculated by taking the ratio of an average of three wavelengths at the peak of each fluorophore emission (474-476 nm for ECFP and 528-530 $\mathrm{nm}$ for EYFP).

Radiopurity calculations. The purity of the ${ }^{228} \mathrm{Ac}$ and ${ }^{90} \mathrm{Y}$ fractions was evaluated based on the decay profile determined by liquid scintillation counting (LSC), using the total counts (0-2000 keV 
for $\beta, 0-1000 \mathrm{keV}$ for $\alpha$ ), to take into account all the isotopes eventually present. Decay curves contained 25-65 points, each corresponding to an LSC measurement and individual background. Decay curves were fitted with the following function.

$A_{\text {total }}=A_{\text {initial }} \times e^{-\lambda \times t}+A_{\text {Residual }}$

Since ${ }^{90} \mathrm{Sr}$ and ${ }^{228} \mathrm{Ra}$ have far longer half-lives than ${ }^{90} \mathrm{Y}$ and ${ }^{228} \mathrm{Ac}$, their activity remains constant and can be determined from the residual activity after the decay of initial ${ }^{90} \mathrm{Y}$ and ${ }^{228} \mathrm{Ac}$, respectively. Due to the secular equilibria ${ }^{90} \mathrm{Sr} /{ }^{90} \mathrm{Y}$ and ${ }^{228} \mathrm{Ra} /{ }^{228} \mathrm{Ac}$, the residual activity corresponds to twice that of ${ }^{90} \mathrm{Sr}$ or ${ }^{228} \mathrm{Ra}$, if present. For example:

$A_{\text {total }}={ }^{228} A c_{\text {initial }}+{ }^{228} R a+{ }^{228} A c_{\text {regenerated }}$

$A_{\text {Residual }}={ }^{228} A c_{\text {regenerated }}+{ }^{228} R a=2 \times{ }^{228} R a$

The fitted values of $A_{\text {initial }}$ and $A_{\text {residual }}$ are directly linked to the purity of initial sample.

Radiopurity $(t=0)=\frac{A_{\text {initial }}-A_{\text {Residual }} / 2}{A_{\text {initial }}}$ 

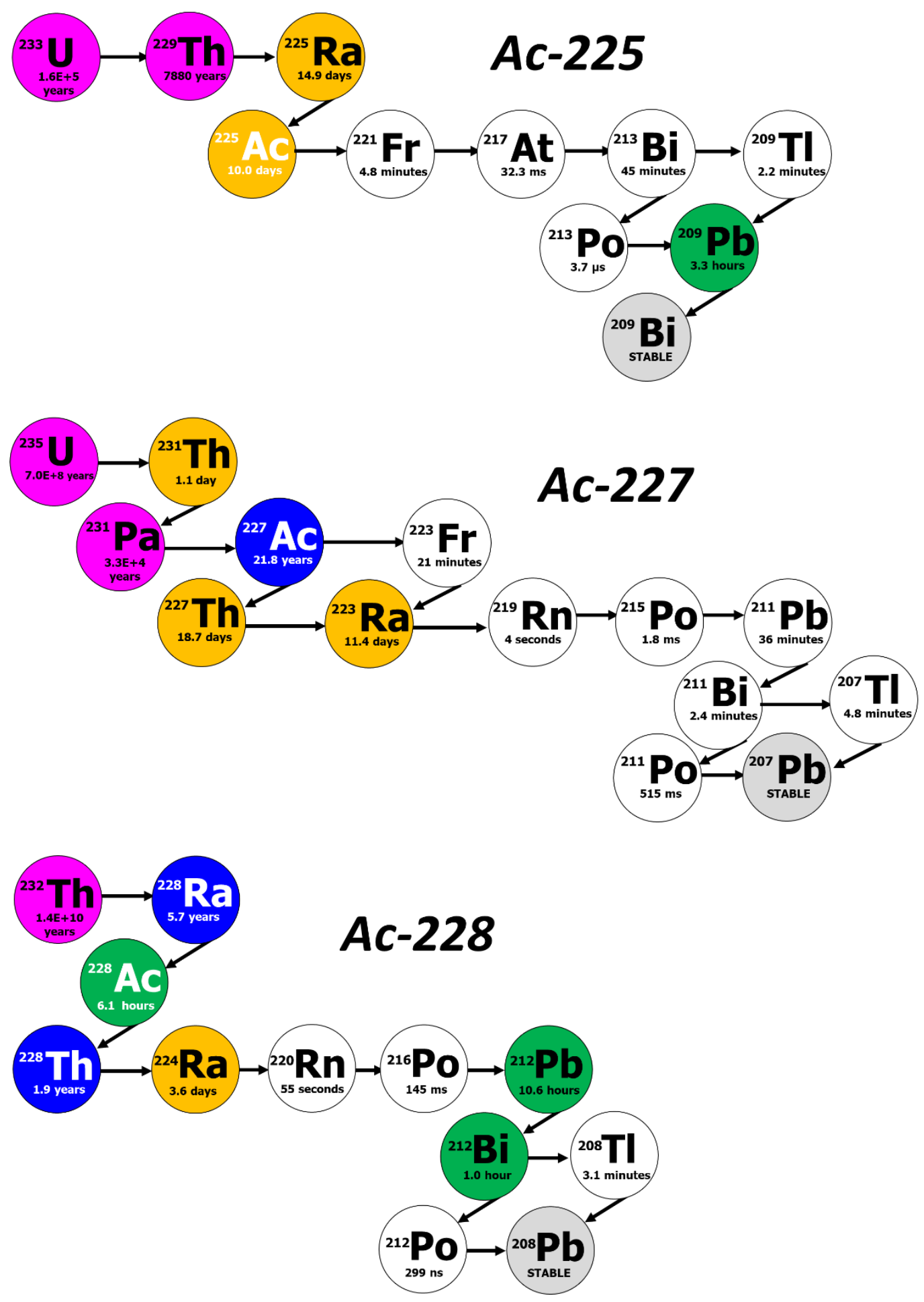

Figure S1. Decay chains comprising the main actinium isotopes. Top: U-233 series leading to Ac-225. Middle: U-235 series leading to Ac-227. Bottom: Th-232 series leading to Ac-228. Important isotopes controlling the activity of the actinium isotopes have been highlighted (Color code: green $\geq 1$ hour; yellow $\geq 1$ day; blue $\geq 1$ year; pink $\geq 100$ years; grey $=$ stable). 

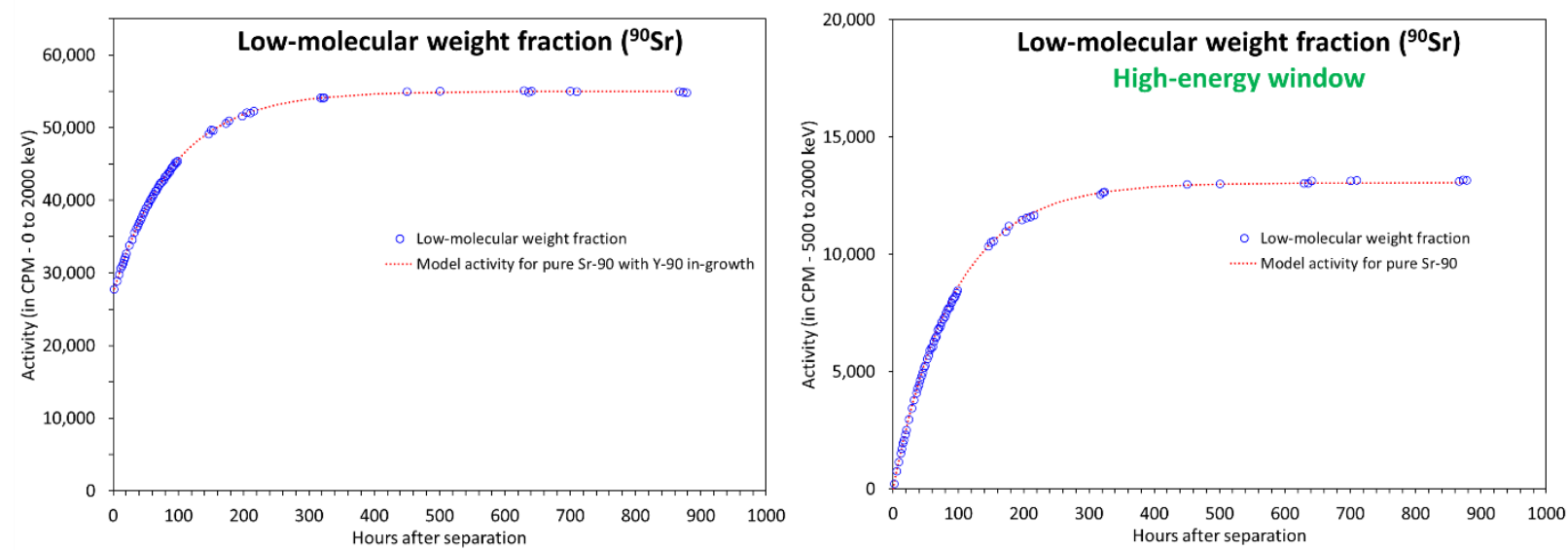

Figure S2. ${ }^{90} \mathrm{Y} /{ }^{90} \mathrm{Sr}$ purification using LanM. Radioactivity of the low-molecular-weight fraction measured by liquid scintillation after elution of an ${ }^{90} \mathrm{Sr} /{ }^{90} \mathrm{Y}$ solution, initially at secular equilibrium, in the presence of LanM (See Figure 2 for corresponding protein fraction). [LanM] $=50 \mu \mathrm{M}$. Buffer: $90 \mathrm{mM}$ $\mathrm{NaCl}, 10 \mathrm{mM}$ HEPES, $\mathrm{pH}=7.0$. Left: Full energy window (0-2000 keV). Right: High-energy window $(500-2000 \mathrm{keV}) .{ }^{90} \mathrm{Sr}$ is a low-energy $\beta$ emitter while ${ }^{90} \mathrm{Y}$ is a high-energy $\beta$ emitter. The absence of activity in the high-energy window just after separation (right) confirm the quantitative removal of ${ }^{90} \mathrm{Y}$ by LanM from the initial pair ${ }^{90} \mathrm{Sr} /{ }^{90} \mathrm{Y}$. As predicted by the Bateman equation, pure ${ }^{90} \mathrm{Sr}$ regenerates ${ }^{90} \mathrm{Y}$, due to a new secular equilibrium. The doubling of the activity after $\sim 600$ hours in the full energy window (left) further confirms the quantitative separation of ${ }^{90} \mathrm{Sr}$ and ${ }^{90} \mathrm{Y}$ using the one-step LanM-based method.
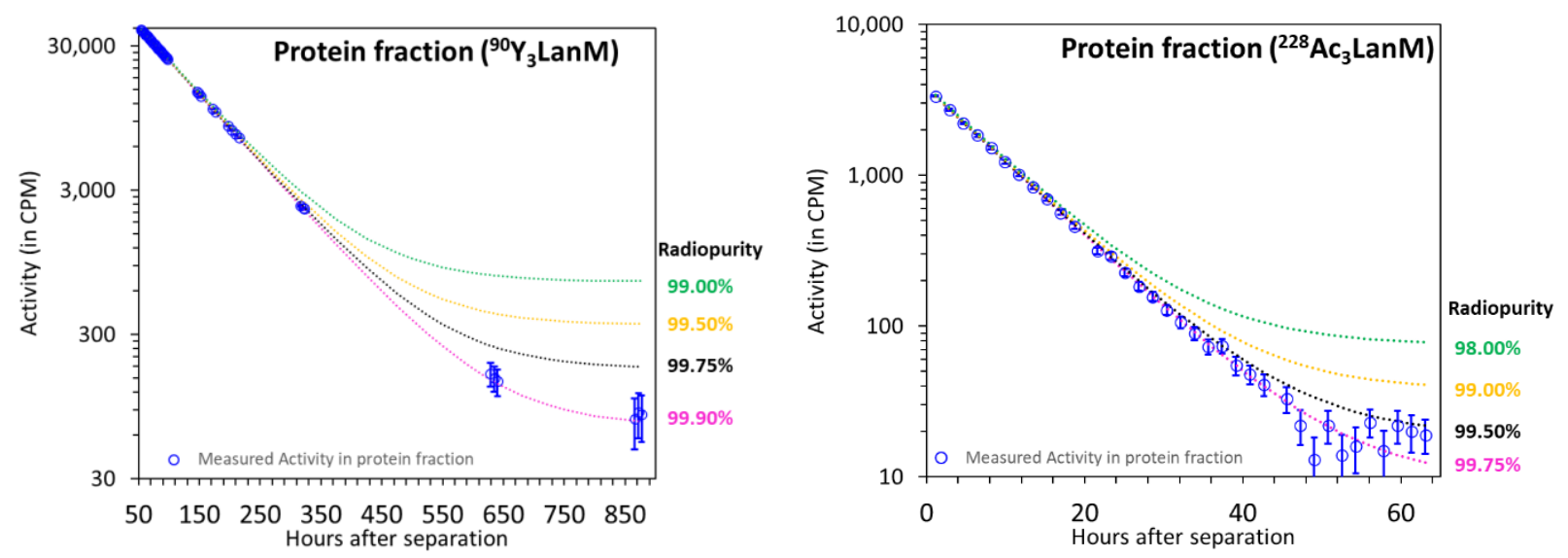

Figure S3. Radiopurity of ${ }^{90} \mathbf{Y}$ and ${ }^{228} \mathrm{Ac}$ fractions. Radioactive decay profiles for the LanM fractions obtained after size exclusion separation (PD-10) of ${ }^{90} \mathrm{Sr} /{ }^{90} \mathrm{Y}$ (left) and ${ }^{228} \mathrm{Ra} /{ }^{228} \mathrm{Ac}$ solutions (right). See main text and Figure 2 for details. The dotted lines correspond to the model decay curves for ${ }^{90} \mathrm{Y}$ and ${ }^{228} \mathrm{Ac}$ at different radiopurity levels. The error bars correspond to at least $\pm 2 \sigma$. 

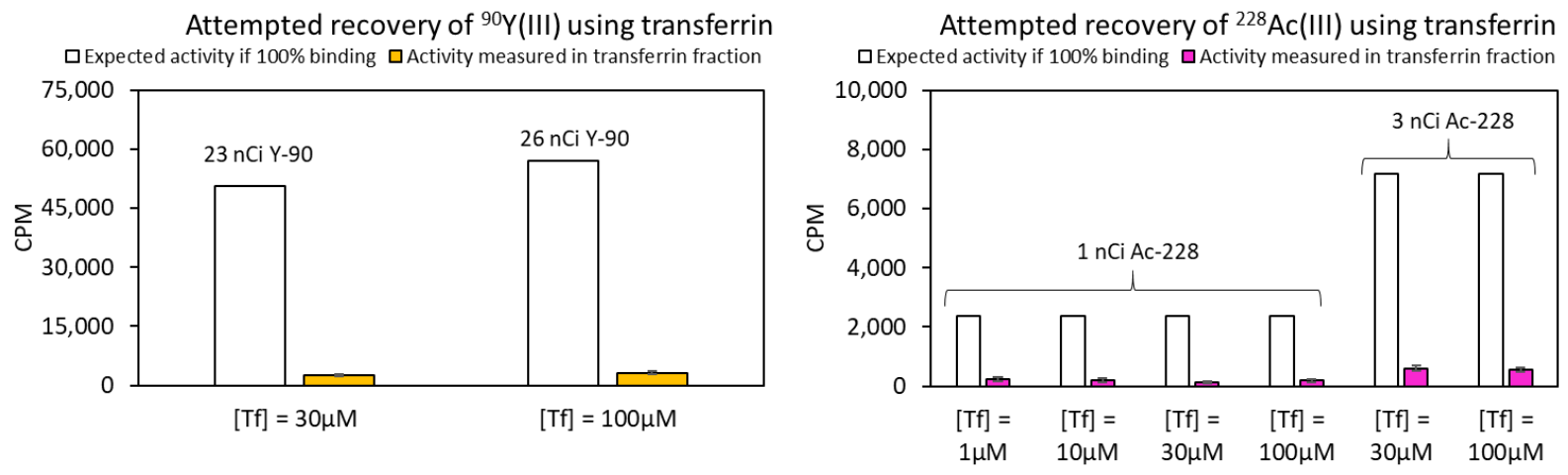

Figure S4. Binding assays between human apo-transferrin (Tf) and ${ }^{90} \mathbf{Y}\left(\right.$ III) or ${ }^{228} \mathrm{Ac}(\mathrm{III})$. Samples were prepared in a buffer suitable for transferrin binding to trivalent f-elements: $\mathrm{pH}=7.4,10 \mathrm{mM}$ synergistic sodium carbonate, $10 \mathrm{mM}$ HEPES, $90 \mathrm{mM} \mathrm{NaCl}$. Samples were incubated at room temperature for at least 2 hours before being eluted through a PD-10 size exclusion column and analyzed by liquid scintillation counting. Activities are corrected to the time of separation between the protein and lowmolecular weight components. Less than $8 \%$ of the targeted isotope was observed in the transferrin fraction in all cases. Some activity could be due to non-specific binding to transferrin.
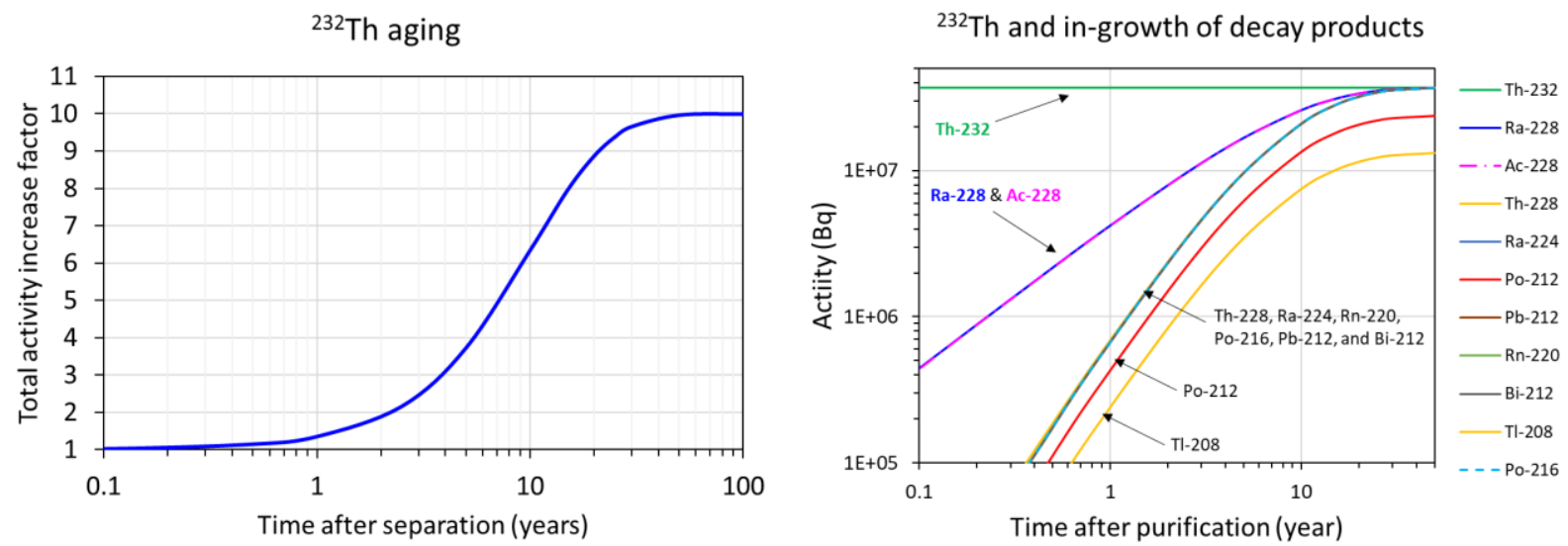

Figure S5. Aging of natural thorium sources $\left({ }^{232} \mathrm{Th}\right)$ and in-growth of its radioactive daughters. Left: Total activity ${ }^{232} \mathrm{Th}+$ daughters) over time. Right: Individual contribution of the daughters over time, starting from a pure ${ }^{232} \mathrm{Th}$ source. The initial activity was arbitrarily set at $1 \mathrm{mCi}$ (or $37 \mathrm{MBq}$ ) of ${ }^{232} \mathrm{Th}$. The activity of each isotope was calculated using the Bateman equation and the half-lives values compiled by National Nuclear Data Center (https://www.nndc.bnl.gov/ensdf/). 
A

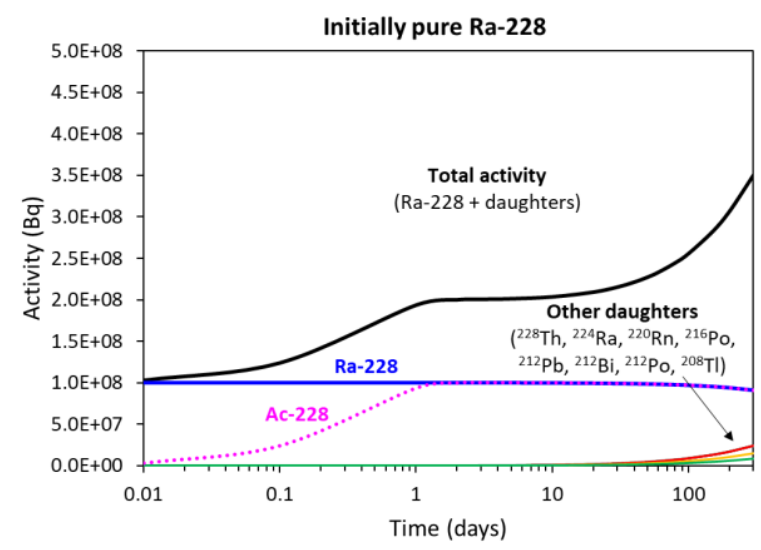

C

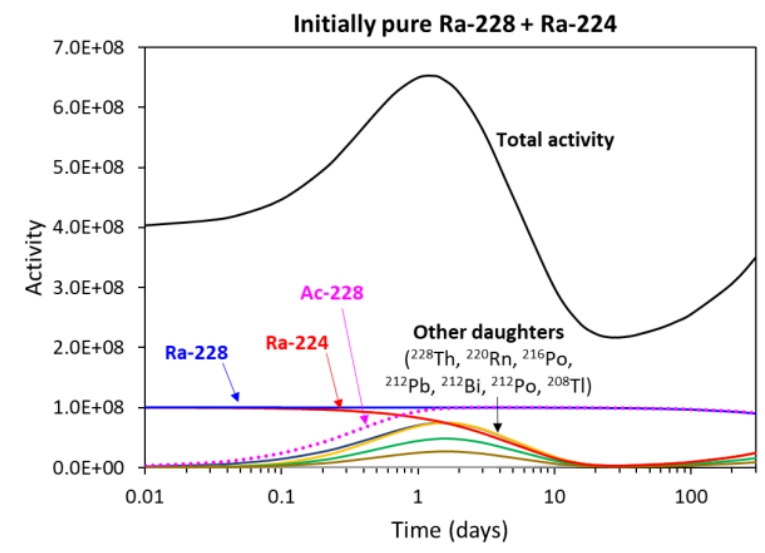

E

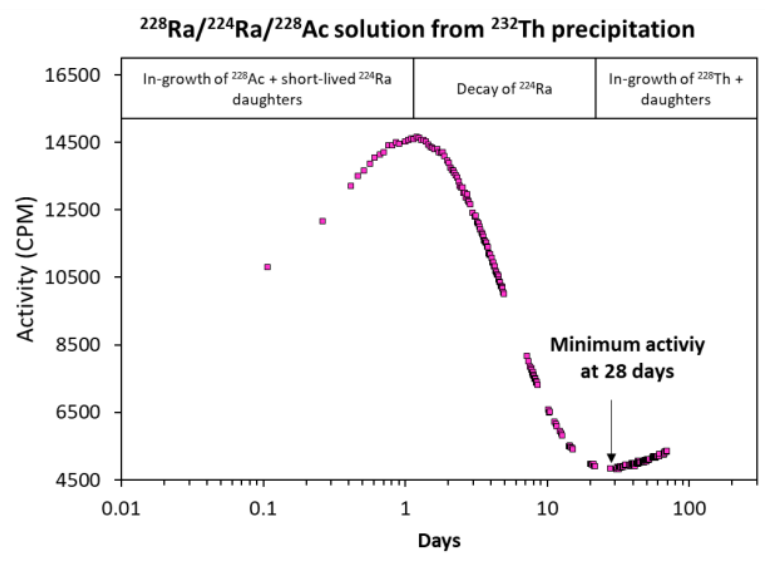

B

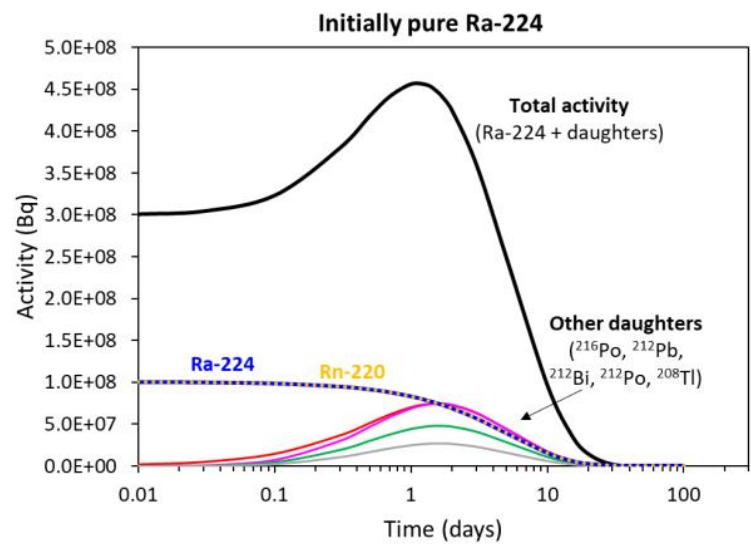

D

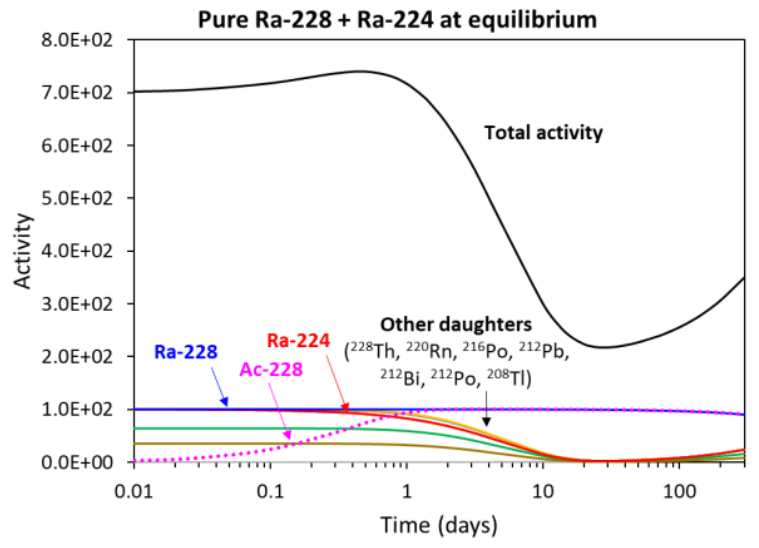

$\mathbf{F}$

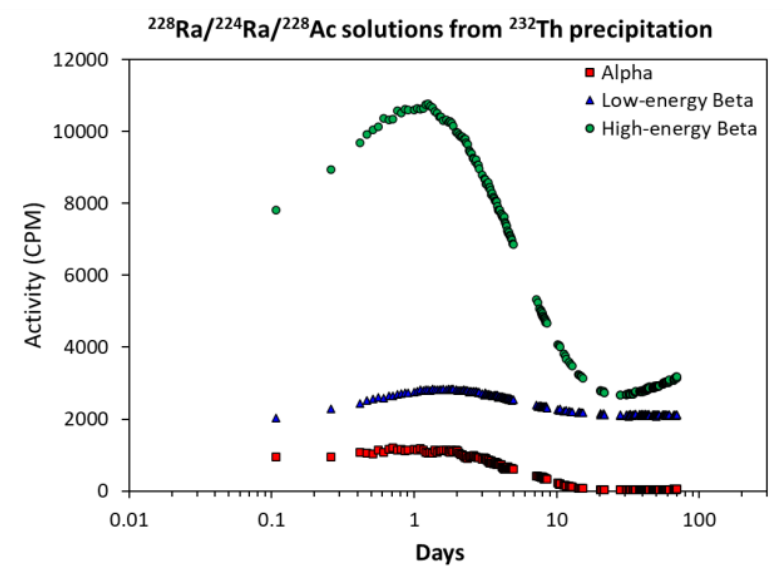

Figure S6. Ageing of radium sources. A) Theoretical evolution of the radioactivity of a ${ }^{228} \mathrm{Ra}$ sample over time. Initial activity arbitrary set to $100 \mathrm{MBq}$ of pure ${ }^{228} \mathrm{Ra}$. B) Theoretical evolution of the radioactivity of a pure ${ }^{224} \mathrm{Ra}$ sample over time. C) Theoretical evolution of the radioactivity of a mixture of ${ }^{224} \mathrm{Ra}$ and ${ }^{228} \mathrm{Ra}$, initially pure. D) Calculated evolution of the radioactivity for a ${ }^{232} \mathrm{Th}$ sample initially at secular equilibrium but from which the thorium and actinium isotopes $\left({ }^{232} \mathrm{Th}+{ }^{228} \mathrm{Th}+{ }^{228} \mathrm{Ac}\right)$ have been selectively removed, leaving ${ }^{228} \mathrm{Ra},{ }^{224} \mathrm{Ra}$ and its six short-lived daughters $\left({ }^{220} \mathrm{Rn},{ }^{216} \mathrm{Po},{ }^{212} \mathrm{~Pb},{ }^{212} \mathrm{Bi},{ }^{212} \mathrm{Po}\right.$, ${ }^{208} \mathrm{Tl}$ ). From its minimum value at $\sim 28$ days, the activity will continuously increase (by about $+250 \%$ ) for the next 4 years and then decay. E) Typical activity profile experimentally measured by liquid scintillation counting for $\mathrm{Ra} / \mathrm{Ac}$ solutions prepared by precipitation of aged ${ }^{232} \mathrm{Th}$ at $\mathrm{pH} 7$. A minimum activity at 28 
days was systematically observed followed by the in-growth of ${ }^{228} \mathrm{Th}$ and its daughters. F) Distribution of the alpha and beta emitters over time for a ${ }^{228} \mathrm{Ra} /{ }^{228} \mathrm{Ac}$ solution obtained following precipitation of aged ${ }^{232} \mathrm{Th}$ at $\mathrm{pH} 7$.

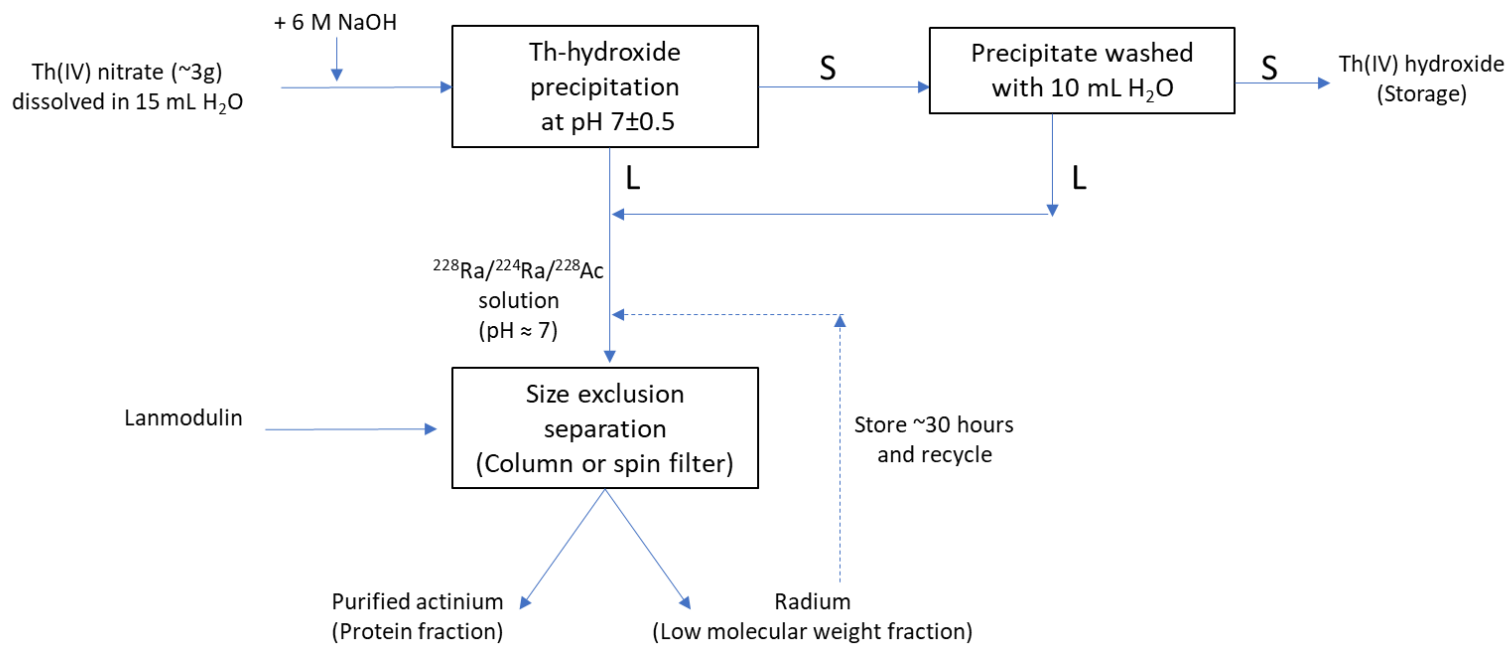

Figure S7. Process scheme for the periodic production of ${ }^{228} \mathrm{Ac}$ solutions form ${ }^{232} \mathrm{Th}$ using LanM. Typically, $3 \mathrm{~g}$ of $\mathrm{Th}\left(\mathrm{NO}_{3}\right)_{4} \cdot \mathrm{nH}_{2} \mathrm{O}$ was dissolved in $15 \mathrm{~mL}$ of water and stirred to obtain a clear solution $(\mathrm{pH}$ $\approx 2.5$ ). Approximately $3 \mathrm{~mL}$ of $6 \mathrm{M} \mathrm{NaOH}$ was added dropwise under vigorous stirring while monitoring the $\mathrm{pH}$. A thick white precipitate appears starting at $\mathrm{pH} \sim 4$. The $\mathrm{pH}$ of the solution was carefully adjusted to $7.0 \pm 0.5$ and maintained for at least $30 \mathrm{~min}$. The slurry was then centrifuged at $9,000 \times g$ for $30 \mathrm{~min}$. The filtrates are recovered. For additional ${ }^{228} \mathrm{Ra}$ recovery, the precipitate can be washed with $10 \mathrm{~mL}$ of $\mathrm{H}_{2} \mathrm{O}$. Additional washes do not significantly improve the recovery yield. $\mathrm{S}=$ solid. $\mathrm{L}=$ liquid.
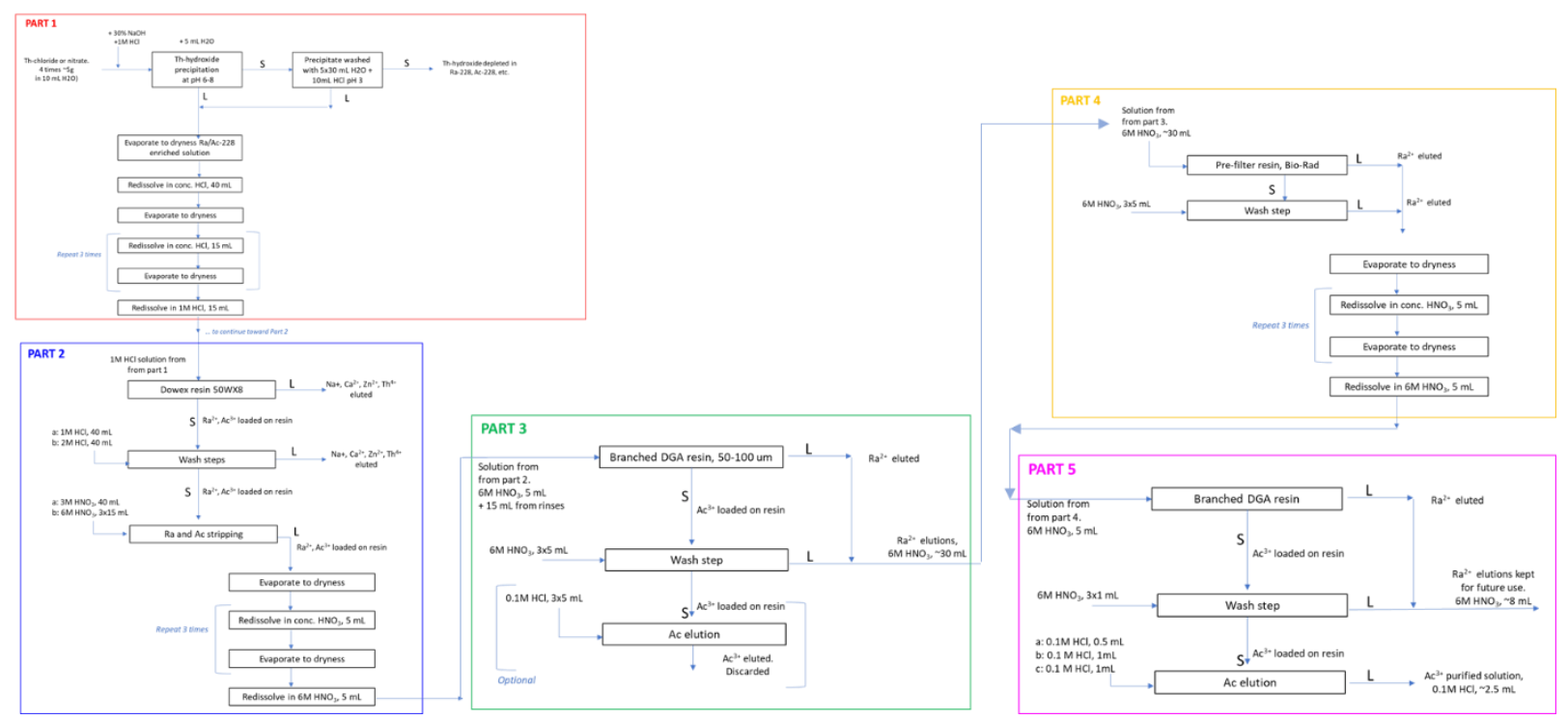

Figure S8. Process scheme of a hydrometallurgical method previously proposed to extract ${ }^{228} \mathrm{Ac}$ from bulk ${ }^{232} \mathrm{Th}$. The details of this method have been published elsewhere. ${ }^{7}$ 


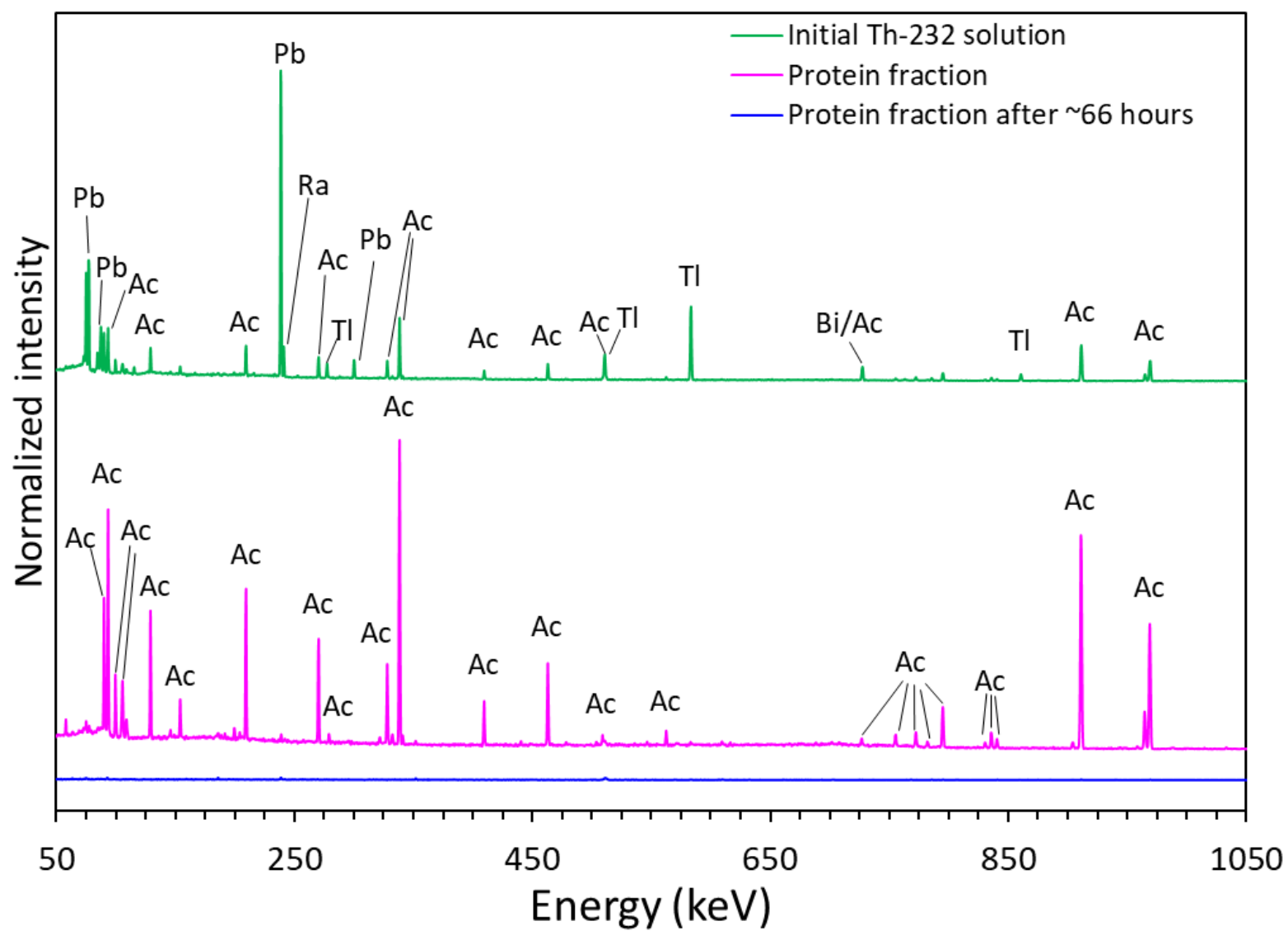

Figure S9. Gamma analysis of ${ }^{228} \mathrm{Ac}$ obtained by LanM-based purification method. Green trace: Gamma spectra of an aged ${ }^{232} \mathrm{Th}$ solution showing the presence of short-lived decay products. Ac $={ }^{228} \mathrm{Ac}$, $\mathrm{Ra}={ }^{224} \mathrm{Ra}, \mathrm{Pb}={ }^{212} \mathrm{~Pb}, \mathrm{Bi}={ }^{212} \mathrm{Bi}, \mathrm{Tl}={ }^{208} \mathrm{Tl}$. Pink trace: Gamma spectra of the LanM fraction analyzed after elution of a ${ }^{228} \mathrm{Ra} /{ }^{228} \mathrm{Ac}$ solution (obtained by precipitation of the initial ${ }^{232} \mathrm{Th}$ solution at $\mathrm{pH}$ ), initially at secular equilibrium, in the presence of LanM. [LanM] $=25 \mu \mathrm{M}$. Buffer: $90 \mathrm{mM} \mathrm{NaCl}, 10 \mathrm{mM}$ HEPES, $\mathrm{pH}=$ 7.0. Separation device: size exclusion column PD-10. The sample was analyzed about 3 hours after elution. Blue trace: Same sample reanalyzed after $\sim 66$ hours. The quantitative decay is what is expected for ${ }^{228} \mathrm{Ac}$ (Half-life $=6.1$ hours). 
A

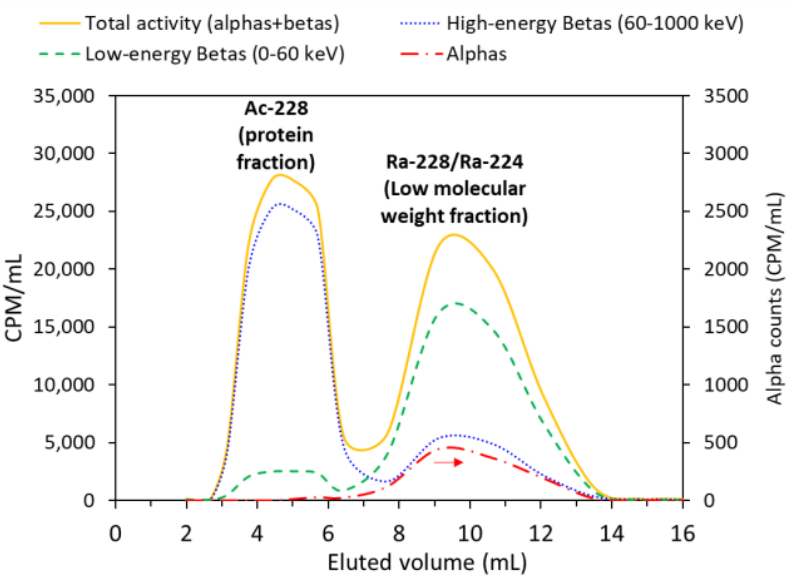

C

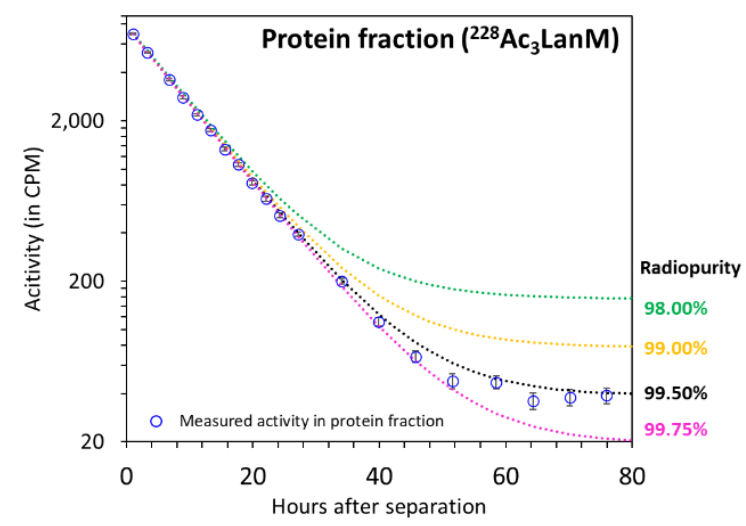

B

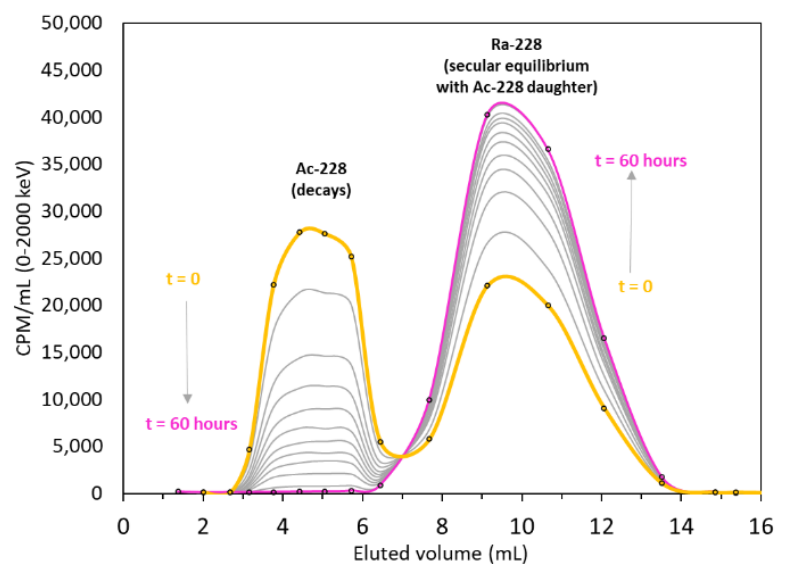

Figure S10. Separation ${ }^{228} \mathrm{Ac} /{ }^{228} \mathrm{Ra} /{ }^{224} \mathrm{Ra}$ using LanM. A) Elution profile of a ${ }^{228} \mathrm{Ra} /{ }^{224} \mathrm{Ra} /{ }^{228} \mathrm{Ac}$ solution in the presence of LanM. $[\mathrm{LanM}]_{\text {initial }}=40 \mu \mathrm{M}$. $\left[{ }^{228} \mathrm{Ac}\right]_{\text {initial }}=25 \mathrm{fM}$. Buffer: $90 \mathrm{mM} \mathrm{KCl}, 10 \mathrm{mM}$ HEPES, $\mathrm{pH}=7.2 .{ }^{228} \mathrm{Ra}$ is a low-energy beta emitter. ${ }^{224} \mathrm{Ra}$ is an alpha emitter. ${ }^{228} \mathrm{Ac}$ is a high-energy beta emitter. The curves showed in panel A are indicative of the total separation between Ra and Ac isotopes. Note that pure Ac-228 inherently gives some counts in the low-energy window (green curve) due to the continuous nature of the beta emission. B) Activity profile monitored at regular intervals for $\sim 60$ hours (About ten ${ }^{228} \mathrm{Ac}$ periods). C) Radioactive decay profile confirming the presence of ${ }^{228} \mathrm{Ac}$ and absence of other isotopes in the protein fraction. Dotted lines are modelled decay curves for ${ }^{228} \mathrm{Ac}\left(\mathrm{t}_{1 / 2}=6.14\right.$ hours) at different radiopurity levels. 

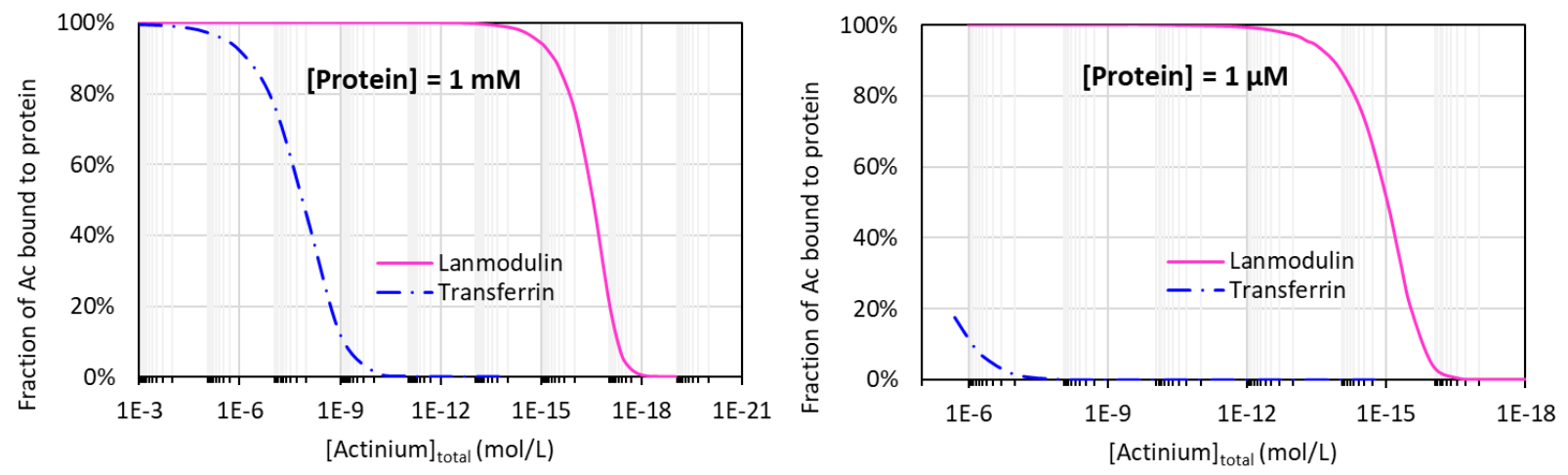

Figure S11. Calculated concentration at which lanmodulin (solid curve) or transferrin (dotted curve) would release actinium, at $\mathrm{pH}$ 7.4. Left: $[\text { Protein }]_{\text {total }}=1 \mathrm{mM}$. Right: $[\text { Protein }]_{\text {total }}=1 \mu \mathrm{M}$. The calculations are based on the experimentally determined stability constant of $A c_{3} \operatorname{LanM}\left(\log \beta_{31}=36.2\right)$ and that of $\mathrm{Ac}_{2}$ Transferrin estimated $\left(\log \beta_{21}=10.9\right.$ - See Figure S18) in the present study. Transferrin starts releasing actinium at concentrations about 9 orders of magnitude before lanmodulin. Calculations were performed with the computer program Hyperquad Simulation and Speciation. ${ }^{5}$
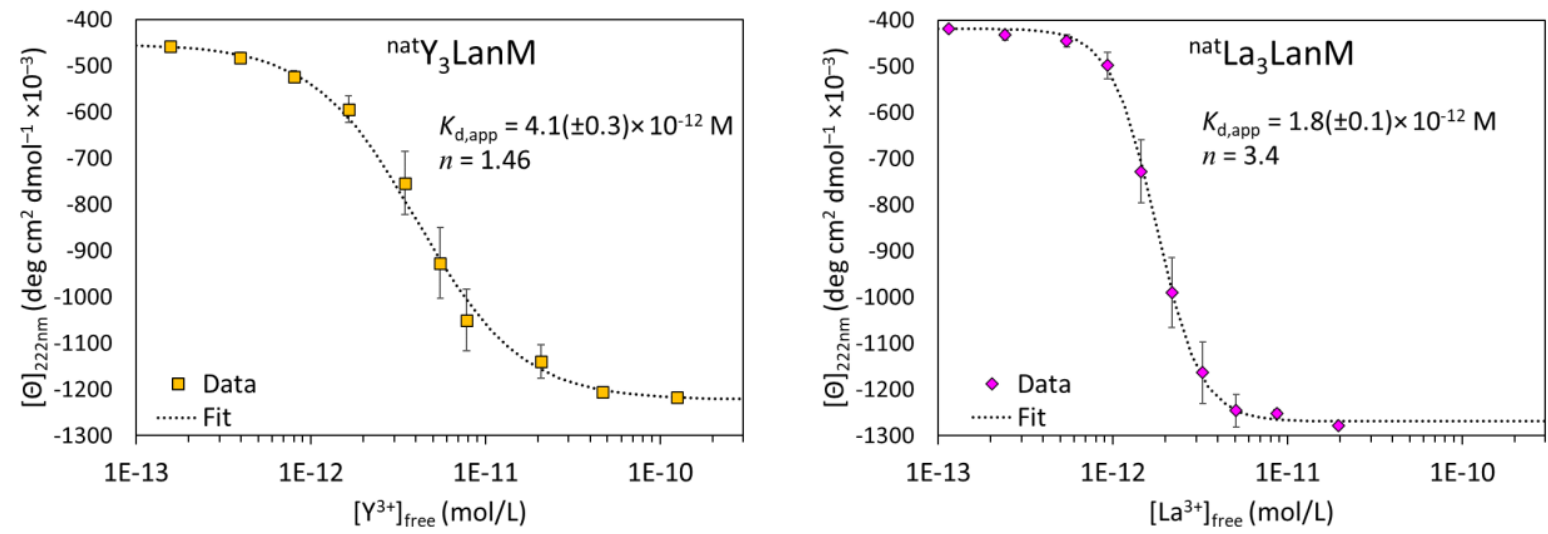

Figure S12. Determination of the stability of nat $\mathbf{Y}_{3} \operatorname{LanM}$ and ${ }^{\text {nat }} \mathrm{La}_{3} \operatorname{LanM}$ by CD. LanM exhibits a nearpicomolar affinity for both $\mathrm{La}^{\mathrm{III}}$ and $\mathrm{Y}^{\mathrm{III}}$ at $\mathrm{pH}$ 7.0. $\left[\theta_{222 \mathrm{~nm}}\right]$ was monitored at various chelator-buffered free metal concentrations using CD spectroscopy, and data were fitted using the Hill equation to determine $K_{\text {d.app }}$ and Hill coefficient $(n)$. (left) LanM-Y ${ }^{\mathrm{III}}$, EDDS (right) LanM-La ${ }^{\mathrm{III}}$, EGTA. Buffer: $10 \mathrm{mM}$ HEPES, $90 \mathrm{mM}$ $\mathrm{NaCl}, \mathrm{pH}$ 7.0. $\mathrm{T}=22{ }^{\circ} \mathrm{C}$. 


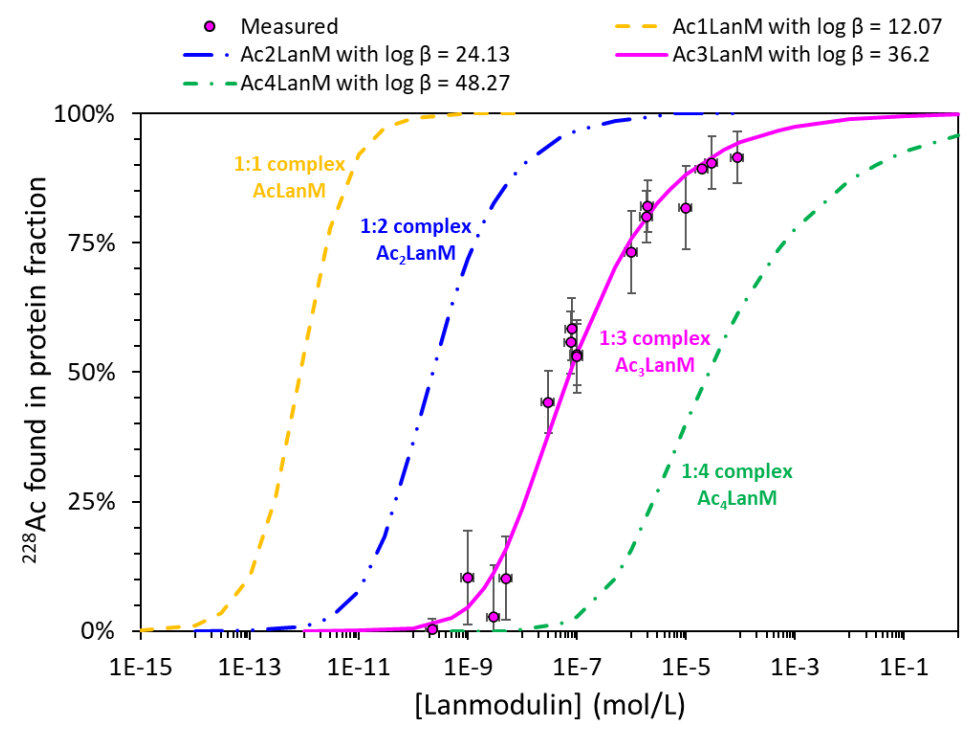

Figure S13. Comparison of the experimental results with speciation models for ${ }^{228} \mathrm{Ac} / \mathrm{LanM}$ complexes of different stoichiometry with the same average affinity per binding site.

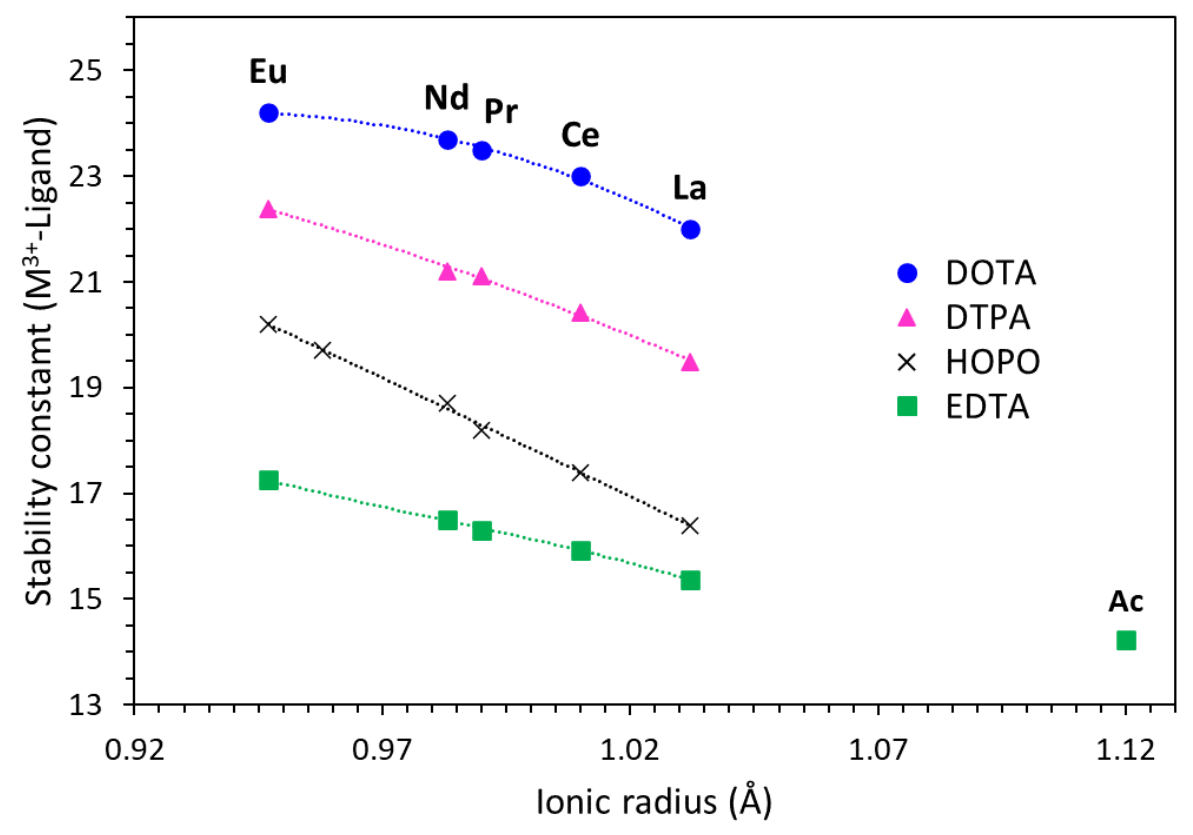

Figure S14. Stability constant, $\log \beta_{11}$, for medically relevant small chelators with early lanthanides and actinium. The variation of $\log \beta_{11}$ as a function of the ionic radius of the metal indicates a decrease in complex stability as the cation gets larger. DOTA $=1,4,7,10$-Tetraazacyclododecane-1,4,7,10-tetraacetic acid. DTPA $=$ Diethylenetriaminepentaacetic acid. EDTA $=$ Ethylenediaminetetraacetic acid. $\mathrm{HOPO}=$ 3,4,3-LI(1,2-Hydroxypyridinonate). The stability constant for [Ac $\left.{ }^{\mathrm{III}} \mathrm{EDTA}\right]^{-}\left(\log \beta_{11}=14.2\right)$ was taken from Makarova et al. ${ }^{8}$ No other stability constant for a complex of actinium with an organic chelator has been experimental determined. The ionic radius values were taken from the review published by Shannon ${ }^{9}$ and are given for a coordination number of 6 . Values for $\mathrm{Ln}(\mathrm{III})$-HOPO have been previously summarized and the $\log \beta_{110}$ for $\mathrm{Ac}(\mathrm{III})-\mathrm{HOPO}$ was estimated to be weak, in the range of 10 to $14 .^{10}$ 

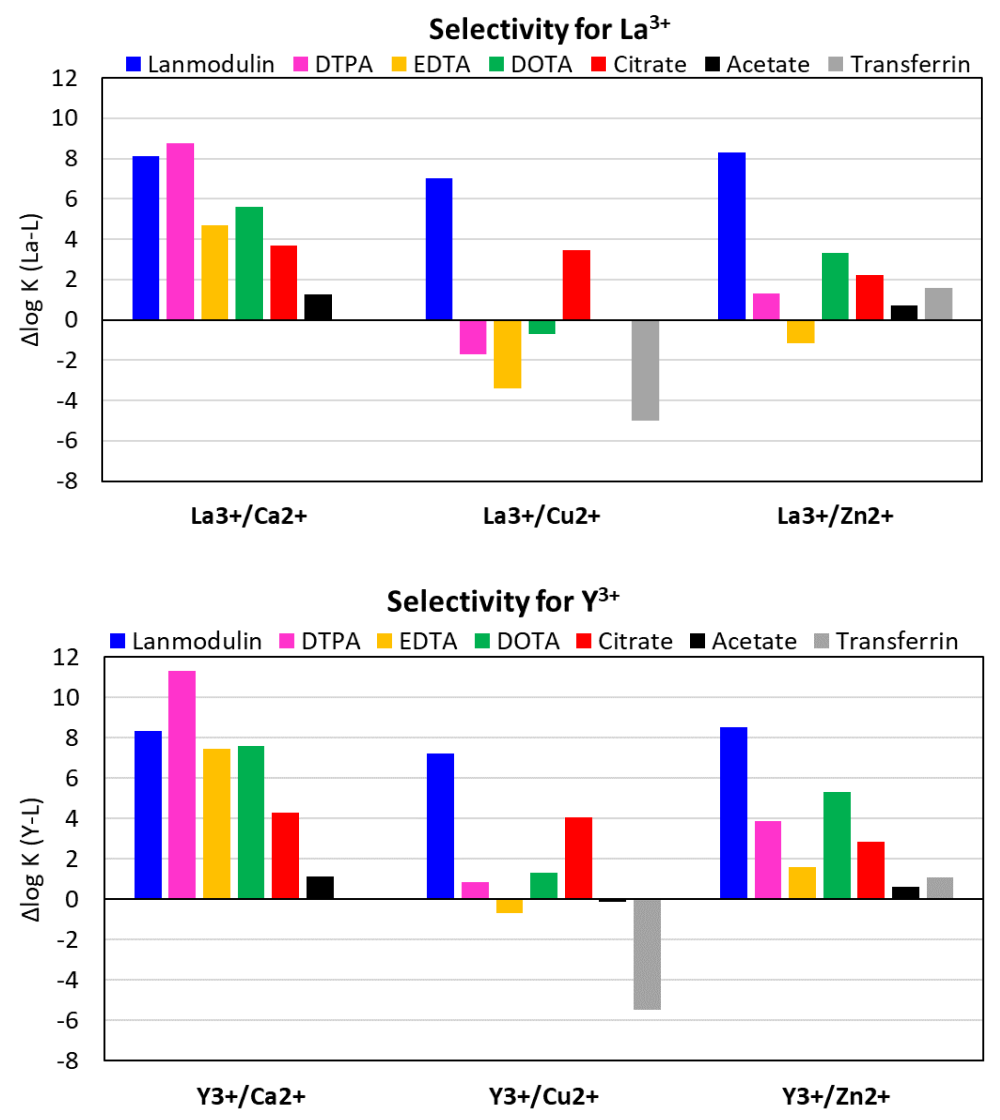

Figure S15. Metal selectivity of small chelators and LanM. Comparison of the thermodynamic selectivity of lanmodulin and medically relevant chelators (transferrin, EDTA, DTPA, DOTA, citrate, acetate) for lanthanum $\left(\mathrm{La}^{3+}\right)$ and yttrium $\left(\mathrm{Y}^{3+}\right)$ against endogenous cations $\left(\mathrm{Ca}^{2+}, \mathrm{Cu}^{2+}, \mathrm{Zn}^{2+}\right)$. In this context, lanthanum is taken as analogue for actinium $\left(\mathrm{Ac}^{3+}\right)$ as the stability constants for $\mathrm{Ac}^{3+}$ with the chelators are unknown (except EDTA ${ }^{8}$ and LanM, this work). Note that the Y-axis is a log scale $(\Delta \log \mathrm{K})$. $\mathrm{K}$ is the formation constant of the 1:1 metal-chelator complexes. A value of zero for $\Delta \log \mathrm{K}$ corresponds to no selectivity. A $\Delta \log \mathrm{K}$ value of 1 indicates a 10 -fold higher affinity for $\mathrm{La}^{3+}$ over the other cation, a $\Delta \log$ $\mathrm{K}$ of 2 indicates a 100-fold higher affinity for $\mathrm{La}^{3+}$, etc. Negative values indicate a preference for the other cation over $\mathrm{La}^{3+}$. Stability constants, other than for LanM, were taken from the NIST Critical database. ${ }^{11}$ The stability constant for LanM were taken from Cotruvo et al. and Deblonde et al. ${ }^{1,12}$ 
A

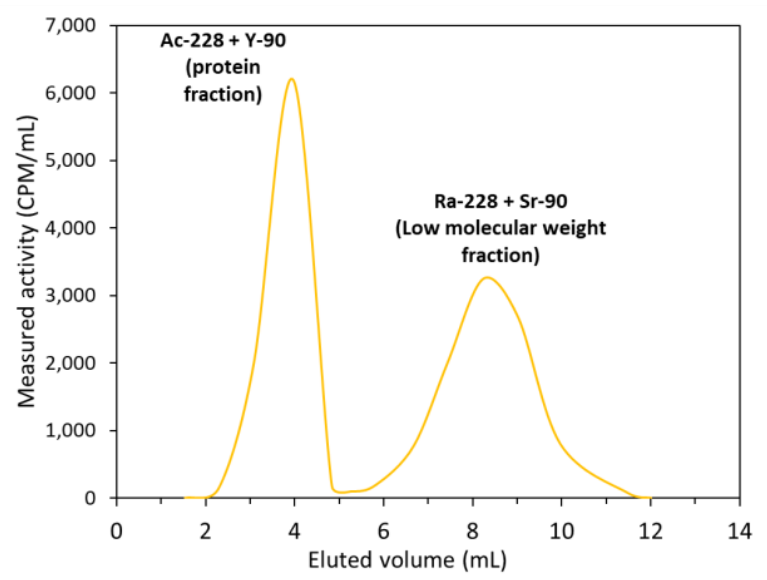

B

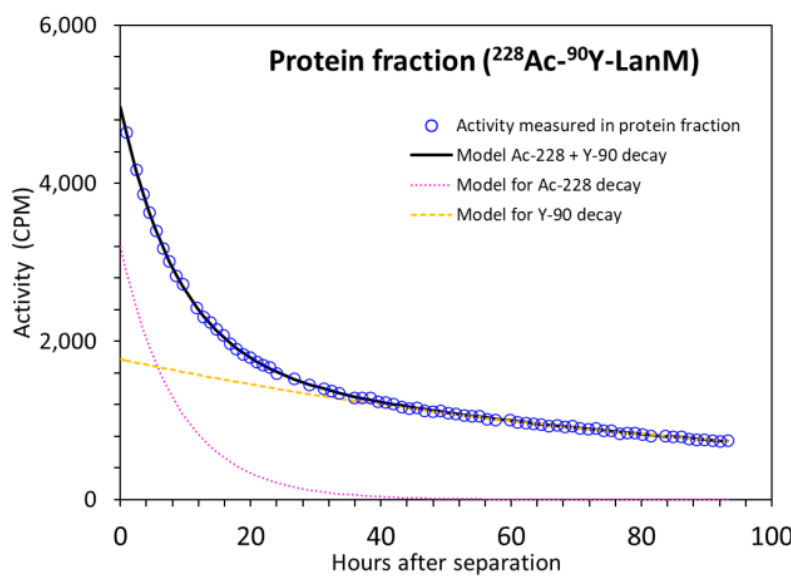

Figure S16. Dual radiolabeling of LanM with ${ }^{228} \mathrm{Ac}$ and ${ }^{90} \mathrm{Y}$ obtained, after 1 elution, from a mixture of ${ }^{228} \mathrm{Ac} /{ }^{228} \mathrm{Ra} /{ }^{90} \mathrm{Sr} /{ }^{90} \mathrm{Y}$. A) Elution profile. B) Radioactive decay curve of the protein fraction. The results indicate that only ${ }^{228} \mathrm{Ac}$ and ${ }^{90} \mathrm{Y}$ were bound to LanM. The other isotopes $\left({ }^{90} \mathrm{Sr},{ }^{228} \mathrm{Ra}\right)$ were carried into the low molecular weight fraction. Size exclusion column: Sephadex PD-10. T $=22^{\circ} \mathrm{C}$. Buffer: $\mathrm{pH} 7.0,90 \mathrm{mM}$ $\mathrm{NaCl}, 10 \mathrm{mM}$ HEPES. Blue circles: experimental data. Solid curve: Calculated total activity for a mixture of pure ${ }^{228} \mathrm{Ac}$ and ${ }^{90} \mathrm{Y}$. Dotted lines: calculated individual contributions of ${ }^{228} \mathrm{Ac}$ and ${ }^{90} \mathrm{Y}$.

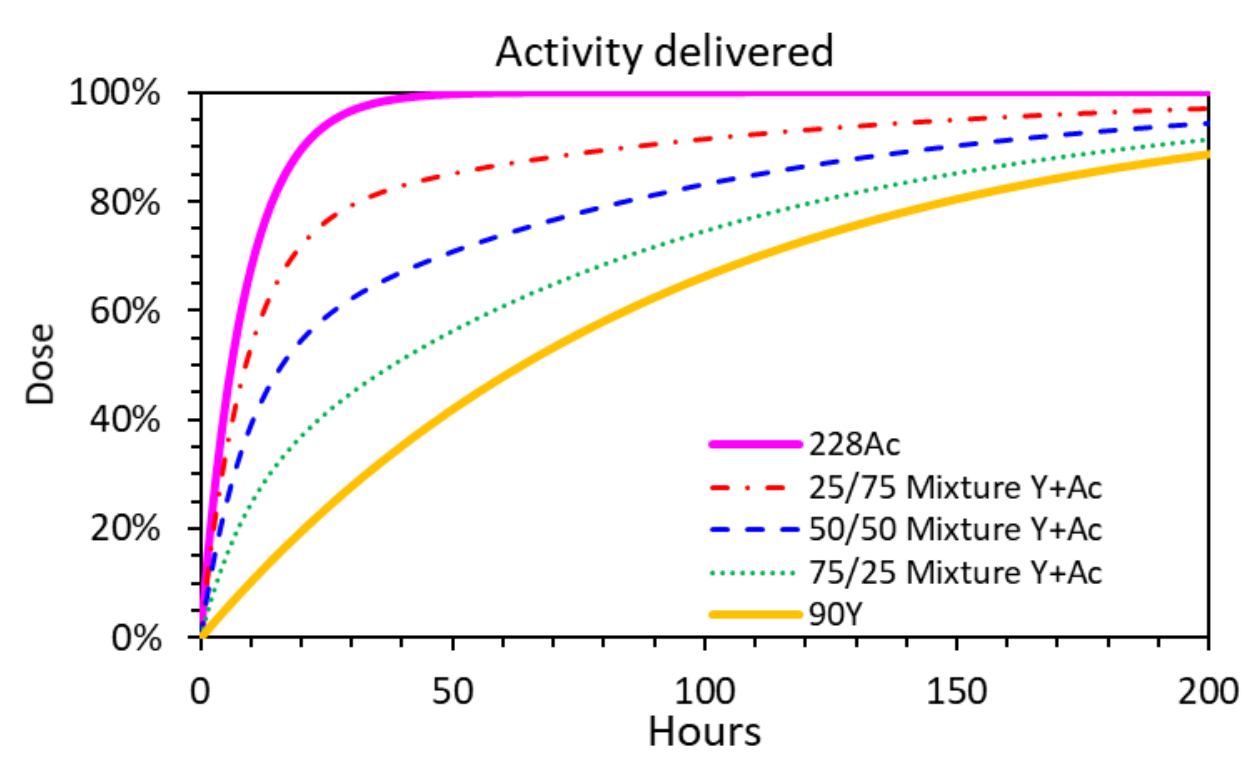

Figure S17. Calculated evolution of the activity delivered by a mixture of radioisotopes, ${ }^{228} \mathrm{Ac}$ and ${ }^{90} \mathrm{Y}$, as a function of time. Variation of the initial ratio allows modulating the duration of the dose as well as the dose profile. 


\section{Transferrin complexes $\left(\mathrm{M}_{2} \mathrm{Tf}\right)$}

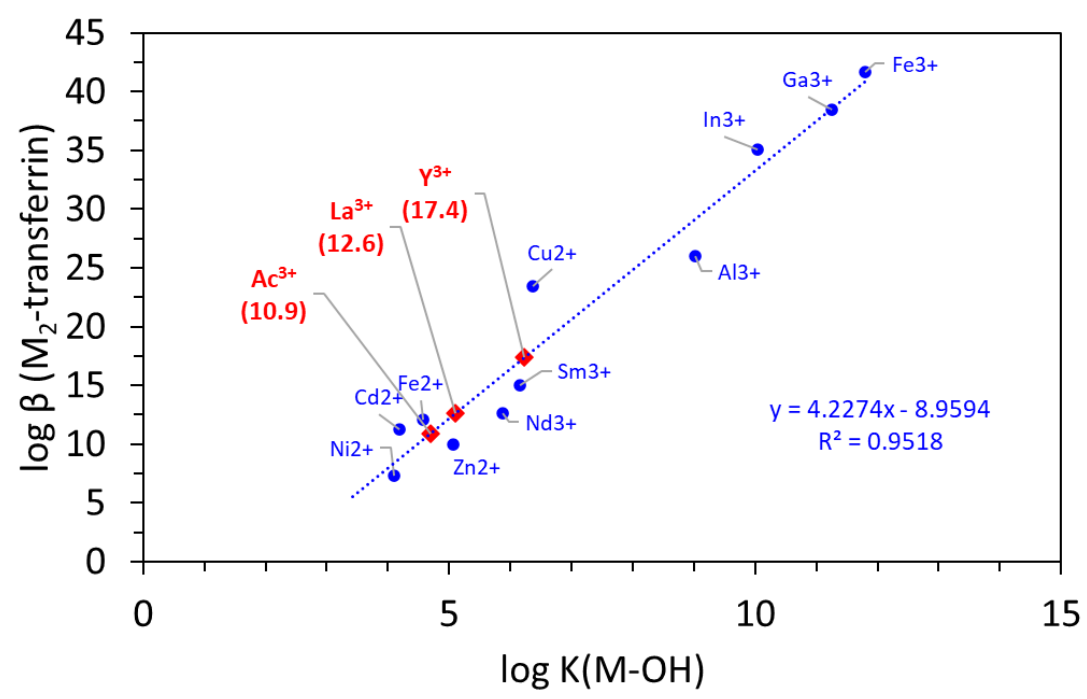

Figure S18. Stability of the actinium complex with transferrin. Empirical correlation between the stability constant of transferrin complexes $\left(\mathrm{M}_{2}\right.$ Transferrin) and the Lewis acidity of the cation. The blue dots correspond to published $\log \beta_{21}$ values for various complexes of transferrin ${ }^{13}$, plotted as function of the first hydrolysis constant of the metal ion. ${ }^{6}$ Based on the periodic trend, the $\log \beta_{21}$ for $\mathrm{Ac}_{2}$ Transferrin is estimated to be 10.9 .

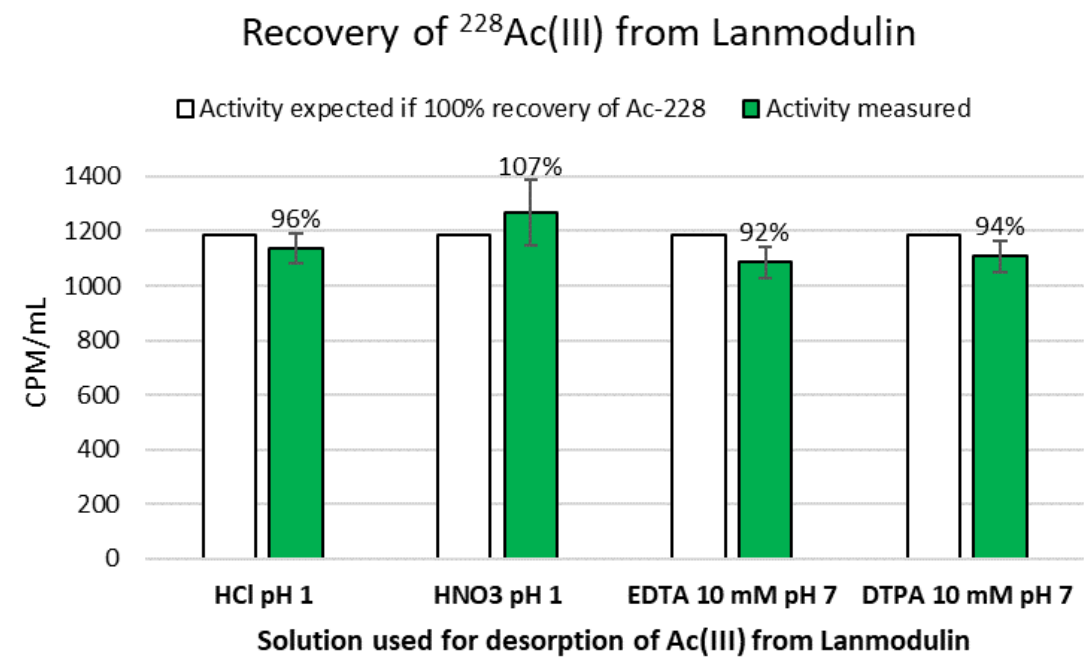

Figure S19. Recovery of actinium bound to lanmodulin. Recovery yield for ${ }^{228} \mathrm{Ac}$ (III) bound to LanM using $\mathrm{HCl} \mathrm{pH} 1, \mathrm{HNO}_{3} \mathrm{pH}$ 1, EDTA $10 \mathrm{mM}$ at $\mathrm{pH}$ 7, or DTPA $10 \mathrm{mM}$ at $\mathrm{pH}$ 7. A solution containing ${ }^{228} \mathrm{Ac}$ (III) bound to LanM was split into four identical aliquots, diluted into solutions containing $\mathrm{HCl}, \mathrm{HNO}_{3}$, EDTA, or DTPA, and incubated for $15 \mathrm{~min}$. [LanM] $=10 \mu \mathrm{M}$. The samples were then centrifuged using a size exclusion filter $(12,000 \mathrm{xg}, 20 \mathrm{~min}$, VivaSpin500, MWCO = $3 \mathrm{kDa})$ and the low-molecular weight fraction was analyzed by liquid scintillation counting. The results indicate that ${ }^{228} \mathrm{Ac}(\mathrm{III})$ was quantitively recovered from LanM in the four conditions tested, yielding protein-free solutions of actinium. Control tests without competing chelator and $\mathrm{pH}>3$ showed that when the radioisotope is bound to LanM no significant activity passes through the size exclusion filter owing to the large size of LanM $(\mathrm{M} \approx 12 \mathrm{kDa})$. 


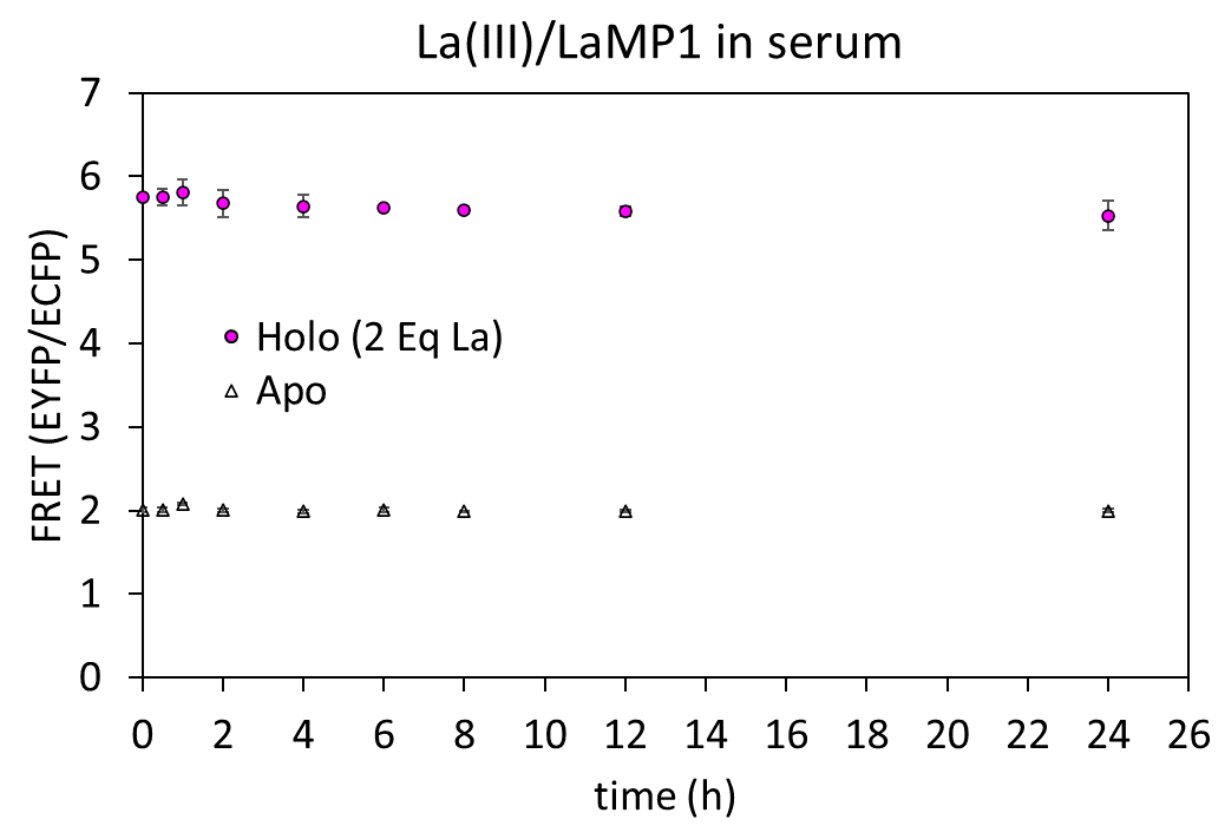

Figure S20. The La(III)-LaMP1 complex exhibits good stability in serum. LaMP1 $(2 \mu \mathrm{M})$, either apo or in the presence of $4 \mu \mathrm{M} \mathrm{La}(\mathrm{III})$, was incubated at $37^{\circ} \mathrm{C}$ in $50 \%$ human serum for $24 \mathrm{~h}$. The ECFP/EYFP FRET ratio was calculated at each time point. As we have shown previously, ${ }^{2}$ the FRET ratio of the lanthanum-bound sensor is higher than the apo sensor. The La(III)-LaMP1 FRET ratios shown here were converted to fraction of the initial ratio in Figure $5 \mathrm{H}$, revealing only a slight decrease $(\sim 5 \%)$ over $24 \mathrm{~h}$. The stable apo-LaMP1 FRET signal indicates negligible proteolysis under these conditions. Error bars correspond to $1 \sigma$ from triplicate measurements. Note that the thermodynamic stability of the $\mathrm{La}_{3} \mathrm{LanM}$ complex is about $5 \times$ higher than that of its corresponding LaMP1 complex. 
Table S1. Amounts of actinium isotopes present in long-lived radionuclides. For comparison purposes, the masses and equivalent radioactive quantities are given for 1 gram of initially pure parent isotope, after 10 years, and at secular equilibrium.

\begin{tabular}{|c|c|c|c|c|c|c|c|}
\hline $\begin{array}{l}\text { Parent } \\
\text { isotope }\end{array}$ & $\begin{array}{l}1 \text { gram of } \\
\text { pure parent } \\
\text { isotope } \\
\text { equals to this } \\
\text { amount of } \\
\text { radioactivity } \\
(\mu \mathrm{Ci})\end{array}$ & $\begin{array}{l}\text { Actinium } \\
\text { daughter }\end{array}$ & $\begin{array}{c}\text { After 10 } \\
\text { years, } \\
\text { secular } \\
\text { equilibrium } \\
\text { with } \\
\text { actinium is } \\
\text { completed } \\
\text { at: }\end{array}$ & $\begin{array}{l}\text { In-growth of } \\
\text { actinium daughter } \\
\text { after } 10 \text { years } \\
(\mu \mathrm{Ci})\end{array}$ & $\begin{array}{l}\text { Mass of } \\
\text { actinium } \\
\text { isotope } \\
\text { after 10 } \\
\text { years } \\
\text { (g) }\end{array}$ & $\begin{array}{c}\text { Time to reach } \\
90 \% \text { of } \\
\text { secular } \\
\text { equilibrium } \\
\text { with actinium } \\
\text { daughter }\end{array}$ & $\begin{array}{c}\text { Mass of } \\
\text { actinium } \\
\text { isotope at } \\
\text { secular } \\
\text { equilibrium } \\
\text { (g) }\end{array}$ \\
\hline Th-232 & 0.110 & Ac-228 & $70 \%$ & 0.077 & $3.5 \mathrm{E}-14$ & $\sim 19$ years & $4.9 \mathrm{E}-14$ \\
\hline $\mathrm{U}-\mathbf{2 3 5}^{\mathrm{a}}$ & 2.2 & Ac-227 & $<0.00003 \%$ & $7 \mathrm{E}-7$ & $9.2 \mathrm{E}-15$ & $\sim 110,000$ years & $3.0 \mathrm{E}-8$ \\
\hline Pa-231 ${ }^{\mathrm{b}}$ & 47,000 & Ac-227 & $27 \%$ & 12,800 & $1.8 \mathrm{E}-04$ & $\sim 73$ years & $6.5 \mathrm{E}-04$ \\
\hline $\mathrm{U}-\mathbf{2 3 3}^{\mathrm{c}}$ & 9,600 & Ac-225 & $0.093 \%$ & 9.0 & $1.5 \mathrm{E}-10$ & $\sim 22,000$ years & $1.6 \mathrm{E}-07$ \\
\hline Th-229d & 196,000 & Ac-225 & $100 \%$ & 196,000 & $3.4 \mathrm{E}-06$ & $\sim 70$ days & $3.4 \mathrm{E}-06$ \\
\hline
\end{tabular}

a: Note that natural uranium only contains $\sim 0.72 \%$ of U-235; along with $99.27 \%$ of U-238 and $<0.01 \%$ of U-234.

b: Pa-231 is naturally present in natural uranium deposits, but only at trace levels as it is a decay product of U-235. Only a handful of institutions in the world currently possess concentrates of $\mathrm{Pa}-231$.

c: U-233 does not occur naturally. U-233 materials, as well as enriched U-235 materials, are highly regulated due to potential nuclear weapons proliferation issues.

d: Th-229 does not occur naturally. It can be harvested from decades-old U-233 sources. 
Table S2. Size exclusion column separations performed with ${ }^{90} \mathrm{Y} /{ }^{90} \mathrm{Sr}$ in the presence of LanM. Samples were eluted through a PD-10 size exclusion column $(8.3 \mathrm{~mL}, \mathrm{MWCO}=5 \mathrm{kDa})$ at various metal and protein concentrations. Series of 10 to 15 fractions were collected for each column experiment. Each fraction was analyzed by liquid scintillation counting in order to determine the partition of ${ }^{90} \mathrm{Y}$ and ${ }^{90} \mathrm{Sr}$ between the protein fractions and the low molecular weight fractions. For each column, speciation calculations of the system Y(III)- $\mathrm{H}_{2} \mathrm{O}$-LanM allows the determination of the stability constant of $\mathrm{Y}_{3} \mathrm{LanM}$. Calculations were performed with the computer program Hyperquad Simulation and Speciation ${ }^{5}$ taking into account the hydrolysis constant of Y(III). The contribution of the hydroxide species was lower than $5 \%$ under these conditions. Buffer: $10 \mathrm{mM}$ HEPES, $90 \mathrm{mM} \mathrm{NaCl}, \mathrm{pH}=7.0$.

\begin{tabular}{|c|c|c|c|c|c|}
\hline $\begin{array}{l}{\left[{ }^{\mathbf{9 0}} \mathbf{Y}\right]} \\
(\mathbf{m o l} / \mathbf{L})\end{array}$ & $\begin{array}{c}{[\mathbf{L a n M}]} \\
(\mathbf{m o l} / \mathbf{L})\end{array}$ & $\begin{array}{c}\text { \%LanM } \\
\text { bound }\end{array}$ & \% Unbound & Obtained $\mathbf{l o g} \boldsymbol{\beta}\left(\mathbf{Y}_{3} \mathbf{L} \mathbf{a n M}\right)$ & Corresponding $\boldsymbol{K}_{\mathbf{d}}$ (in $\left.\mathbf{p M}\right)$ \\
\hline $1.22 \mathrm{E}-11$ & $5.00 \mathrm{E}-05$ & $>95.8 \%$ & $4.2 \%$ & $>30$ & $<100$ \\
\hline $6.11 \mathrm{E}-14$ & $1.00 \mathrm{E}-06$ & $78.0 \%$ & $22.0 \%$ & 34.0 & 4.6 \\
\hline $6.11 \mathrm{E}-15$ & $1.00 \mathrm{E}-06$ & $51.6 \%$ & $48.4 \%$ & 34.8 & 2.5 \\
\hline $1.22 \mathrm{E}-14$ & $1.00 \mathrm{E}-09$ & $4.7 \%$ & $95.3 \%$ & $<36$ & $>1$ \\
\hline $3.05 \mathrm{E}-14$ & $1.00 \mathrm{E}-06$ & $72.0 \%$ & $28.0 \%$ & 34.3 & 3.7 \\
\hline $3.05 \mathrm{E}-14$ & $1.00 \mathrm{E}-07$ & $62.6 \%$ & $37.4 \%$ & 34.8 & 2.5 \\
\hline $3.05 \mathrm{E}-14$ & $1.00 \mathrm{E}-08$ & $11.1 \%$ & $88.9 \%$ & 34.0 & 4.6 \\
\hline $3.05 \mathrm{E}-14$ & $1.00 \mathrm{E}-05$ & $79.7 \%$ & $20.3 \%$ & 33.7 & 5.8 \\
\hline $6.11 \mathrm{E}-14$ & $1.00 \mathrm{E}-05$ & $84.6 \%$ & $15.4 \%$ & 33.6 & 6.3 \\
\hline $6.11 \mathrm{E}-14$ & $2.00 \mathrm{E}-05$ & $83.1 \%$ & $16.9 \%$ & 33.2 & 6.6 \\
\hline $6.11 \mathrm{E}-14$ & $2.00 \mathrm{E}-05$ & $86.7 \%$ & $13.3 \%$ & 33.5 & 4.6 \\
\hline $6.11 \mathrm{E}-14$ & $2.00 \mathrm{E}-05$ & $91.7 \%$ & $8.3 \%$ & 34.0 & 7.9 \\
\hline $6.11 \mathrm{E}-14$ & $2.00 \mathrm{E}-05$ & $84.5 \%$ & $15.5 \%$ & 33.3 & 4.6 \\
\hline $6.11 \mathrm{E}-14$ & $2.00 \mathrm{E}-05$ & $91.8 \%$ & $8.2 \%$ & 34.0 & $<10$ \\
\hline $2.04 \mathrm{E}-12$ & $2.00 \mathrm{E}-05$ & $98.7 \%$ & $1.3 \%$ & $>33$ & $\mathbf{4 . 3 1}$ \\
\hline & & & Average & $\mathbf{3 3 . 9}$ & $\mathbf{1 . 5}$ \\
\hline & & & StDev & $\mathbf{0 . 5}$ & \\
\hline
\end{tabular}




\section{References}

1. Cotruvo, J. A. Jr., Featherston, E. R., Mattocks, J. A., Ho, J. V. \& Laremore, T. N. Lanmodulin: A Highly Selective Lanthanide-Binding Protein from a Lanthanide-Utilizing Bacterium. J. Am. Chem. Soc. 140, 15056-15061 (2018).

2. Mattocks, J. A., Ho, J. V. \& Cotruvo, J. A. Jr. A Selective, Protein-Based Fluorescent Sensor with Picomolar Affinity for Rare Earth Elements. J. Am. Chem. Soc. 141, 2857-2861 (2019).

3. Featherston, E. R., Mattocks, J. A., Tirsch, J. L. \& Cotruvo, J. A. Chapter Six - Heterologous expression, purification, and characterization of proteins in the lanthanome. in Methods in Enzymology (ed. Cotruvo, J. A.) vol. 650 119-157 (Academic Press, 2021).

4. Gunnink, R., Ruhter, W. D. \& Niday, J. B. Operations guide for GRPANL (GRouP ANaLysis): A suite of computer programs for analyzing complex Ge and alpha-particle detector spectra: Volume 2. https://www.osti.gov/biblio/6775430 (1988).

5. Alderighi, L. et al. Hyperquad simulation and speciation (HySS): a utility program for the investigation of equilibria involving soluble and partially soluble species. Coordination Chemistry Reviews 184, 311-318 (1999).

6. Brown, P. L. \& Ekberg, C. Actinide Metals. in Hydrolysis of Metal Ions 325-432 (John Wiley \& Sons, Ltd, 2016). doi:10.1002/9783527656189.ch9.

7. Aldrich, K. E. et al. Preparation of an Actinium-228 Generator. Inorg. Chem. 59, 3200-3206 (2020).

8. Makarova, T. P., Sinitsyna, G. S., Stepanov, A. V., Shestakova, I. A. \& Shestakova, B. I. Complex formation of actinium. I. Determination of the stability constants of ethylenediaminetetraacetate complexes of actinium and its separation from lanthanum in solutions of EDTA by the method of electromigration. Soviet Radiochemistry 14, 555-557 (1972).

9. Shannon, R. D. Revised Effective Ionic Radii and Systematic Studies of Interatomie Distances in Halides and Chaleogenides. Acta crystallographica A32, 751-767 (1976). 
10. Deblonde, G. J.-P., Ricano, A. \& Abergel, R. J. Ultra-selective ligand-driven separation of strategic actinides. Nat Commun 10, 2438 (2019).

11. Johnson, S. G. NIST46 - NIST Critically Selected Stability Constants of Metal Complexes: (2013).

12. Deblonde, G. J.-P. et al. Selective and Efficient Biomacromolecular Extraction of Rare-Earth Elements using Lanmodulin. Inorg. Chem. 59, 11855-11867 (2020).

13. Sun, H., Li, H. \& Sadler, P. J. Transferrin as a Metal Ion Mediator. Chem. Rev. 99, 2817-2842 (1999). 
Page 46 of 46 